\title{
An integrated gasification plant for electric power generation from wet biomass: toward a sustainable production in the olive oil industry
}

\author{
Roque Aguado $^{1} \cdot$ David Vera $^{1}\left[\right.$ [ Francisco Jurado ${ }^{1} \cdot$ Gabriel Beltrán $^{2}$
}

Received: 27 September 2021 / Revised: 10 December 2021 / Accepted: 13 December 2021

(c) The Author(s) 2022

\begin{abstract}
This research work proposes an integrated gasification plant for simultaneous generation of renewable electricity and drying of olive pomace, a thick sludge with a moisture content close to 60-70\% (wet basis), which constitutes by far the most abundant by-product in the Spanish olive oil industry. Due to its massive rate of production and increasing associated transportation costs, olive pomace management currently represents a substantial expense for oil mills. The integrated gasification plant, which can be installed directly at oil mills, consists of a pelletizer, a downdraft gasifier under autothermal operation fueled with dried olive pomace pellets, a producer gas cooling and cleaning unit and a microturbine as power generation unit. The wet olive pomace continuously produced in oil mills is eventually dried in a co-current flow rotary drum dryer with the hot exhaust gases leaving the microturbine at temperatures close to $300{ }^{\circ} \mathrm{C}$, allowing a self-sufficient operation of the integrated gasification plant. The integrated gasification plant was modeled using Aspen Plus ${ }^{\circledR}$ process simulator. The developed model was validated against experimental and simulation results of relevant works. Under optimum operating conditions, the electrical efficiency of the proposed plant is $18.8 \%$, while the additional drying stage allows achieving an overall efficiency of $51.0 \%$. Electricity consumption by the pelletizer and ancillary equipment represents $10-20 \%$ of the net electric power generation from the microturbine. However, since the integrated gasification plant is fueled with an inexpensive by-product of olive oil production that is massively produced on-site, the plant performance parameters are remarkably satisfactory.
\end{abstract}

Keywords Olive pomace $\cdot$ Downdraft gasifier $\cdot$ Producer gas $\cdot$ Microturbine $\cdot$ Rotary drum dryer $\cdot$ Waste-to-energy

\section{Introduction}

David Vera

dvera@ujaen.es

Roque Aguado

ramolina@ujaen.es

Francisco Jurado

fjurado@ujaen.es

Gabriel Beltrán

gabriel.beltran@juntadeandalucia.es

1 Departamento de Ingeniería Eléctrica, Escuela Politécnica Superior de Linares, Universidad de Jaén, Avda. de la Universidad s/n, 23700 Linares, Spain

2 Junta de Andalucía, IFAPA Centro "Venta del Llano", P.O. Box 50, 23620 Mengíbar, Spain
The cultivation of olive trees (Olea europaea L.) for the production of olive oil is an established practice in the Mediterranean basin for millennia. The largest area under olive groves worldwide is currently located in Spain, with over 2.5 million hectares [1], accounting for more than half of the total area dedicated to this crop in Europe. In terms of olive oil production, Spain is also the world's leading country, with a yearly production of about 1.35 million metric tons on average in the last 10 years, representing around $50 \%$ of the world production [2]. The Spanish olive oil sector has a centralized distribution, with over 1800 olive mills in operation, being Andalusia the most representative region with about 800 large and medium-size mills and approximately $75 \%$ of the national olive oil production [2, 3]. Up until the 1990s, the Spanish olive oil industry was based on the three-phase 
decanting system [4]. Although three-phase decanters have the highest olive oil recovery efficiency, they produce the highest amount of waste streams [3]. After decades of substantial investments in the modernization of oil mills in order to reduce freshwater consumption and the quantity of olive mill waste streams, nowadays more than $90 \%$ of olive mills in Spain are based on the two-phase extraction process, which constitutes the main extraction system with over $95 \%$ of the total olive oil production [5]. However, the olive oil sector still faces additional challenges toward environmental sustainability concerning waste management and recovery, as well as energy efficiency improvement [6].

The Spanish olive oil industry generates a wide variety of wastes and by-products. Their rate of production and physicochemical properties depend on the olive oil extraction method. Olive pomace (also referred to as wet pomace, two-phase olive mill waste or alperujo) represents the most abundant residue in the Spanish olive oil industry due to its massive rate of production in oil mills. After the two-phase extraction process, roughly $70-75 \%$ by weight of processed olives becomes pomace, a thick sludge with a high moisture content (60-70\%, wet basis) made up of olive pulp, skin, crushed pits and around $2-4 \%$ by weight of olive oil $[4,6,7]$. The main physicochemical properties of olive pomace are reported in Table 1 [8].

Olive pomace must be continuously transported to olive pomace oil extraction plants in cargo trucks, because its accumulation at oil mills can cause production stoppages and substantial economic losses [9]. In these plants, the wet olive pomace from oil mills is deposited in large ponds for subsequent drying and eventual extraction of crude olive pomace oil, generating exhausted olive pomace (also called orujillo) as a by-product. In order to extract the remaining olive oil contained in the wet pomace, a previous energy-intensive drying stage is required. The required thermal energy for such purpose is generally supplied by burning large amounts of exhausted pomace in furnaces or even by using fossil fuels such as natural gas in reciprocating internal combustion engines, leading to large amounts of carbon dioxide emissions into the atmosphere [10]. Drying of wet pomace has been traditionally performed in large-scale continuous rotary drum dryers through which an air stream at high inlet temperatures $\left(400-800{ }^{\circ} \mathrm{C}\right)$ and velocities $(1-7 \mathrm{~m} / \mathrm{s})$ is driven [9]. The dried pomace is eventually subjected to a solid-liquid extraction process of the crude pomace oil with an organic solvent, usually hexane.

As shown in Fig. 1, in recent years the increasing Spanish olive oil production has contributed to a sharp growth in the yearly production of wet olive pomace [2], which represents a remarkable increase in the associated management expenses for both oil mills and pomace oil extractors. It is noteworthy that until the 1990s, the Spanish olive oil production was based on the three-phase extraction process, which yields a much smaller amount of a similar by-product known as three-phase olive mill waste or olive cake. This by-product from three-phase olive oil production is characterized by a moisture content of around 40-45\% [4], while olive pomace has a moisture content close to $60-70 \%$ or even higher.

This research work proposes an alternative approach for olive pomace management, where the wet pomace being continuously produced in oil mills at high rates is directly dried on site, instead of being transported for subsequent drying in olive pomace oil extraction plants. The required heat for the drying process is supplied by means of the hot exhaust gases leaving a downdraft gasifier-microturbine combined system fueled with dried olive pomace pellets. In downdraft gasifiers, a carbonaceous solid fuel such as olive pomace is partially oxidized and converted into a gaseous fuel, usually termed as producer gas or synthesis gas (syngas) $[11,12]$. A gasifying agent (air, pure oxygen and/or steam) is required so as to transform the high-carbon solid feedstock into gaseous fuel through a series of exothermic and endothermic reactions, which determine four different stages depending on the temperature at which they occur: drying, pyrolysis, combustion/oxidation and reduction [11]. Gasification with air as gasifying agent is an autothermal process, whereby the exothermic combustion reactions provide enough energy for the endothermic reactions responsible for the producer gas formation to take place. The producer gas from gasification, once cooled and cleaned, can be used as fuel in gas engines or microturbines for electric and/or thermal power generation.
Table 1 Physicochemical properties of olive pomace (two-phase extraction process)

\begin{tabular}{|c|c|c|c|c|c|}
\hline \multicolumn{2}{|l|}{ Proximate analysis (wt.\%) } & \multicolumn{2}{|c|}{$\begin{array}{l}\text { Ultimate analysis } \\
\text { (wt.\%, dry basis) }\end{array}$} & \multicolumn{2}{|l|}{ Other properties } \\
\hline \multirow[t]{2}{*}{ Moisture $(W)$, as received } & $60-70(w p)^{\mathrm{a}}$ & Carbon & 51.3 & $\mathrm{LHV}$, as received $(\mathrm{MJ} / \mathrm{kg})$ & 17.5 \\
\hline & $10-15(d p)^{\mathrm{b}}$ & Hydrogen & 6.4 & considering $W=12.5 \%$ & \\
\hline Ash, dry basis & 5 & Nitrogen & 2.0 & Ash melting point $\left({ }^{\circ} \mathrm{C}\right)$ & $>1000$ \\
\hline Volatile matter, dry basis & 77.4 & Sulfur & 0.3 & Bulk density $\left(\mathrm{kg} / \mathrm{m}^{3}\right)$ & 780 \\
\hline Fixed carbon, dry basis & 17.6 & $\begin{array}{l}\text { Oxygen (by } \\
\text { difference) }\end{array}$ & 35.0 & Avg. particle size (mm) & $1-5$ \\
\hline
\end{tabular}

${ }^{\mathrm{a}} w p=$ wet olive pomace, ${ }^{\mathrm{b}} d p=$ dried olive pomace. 


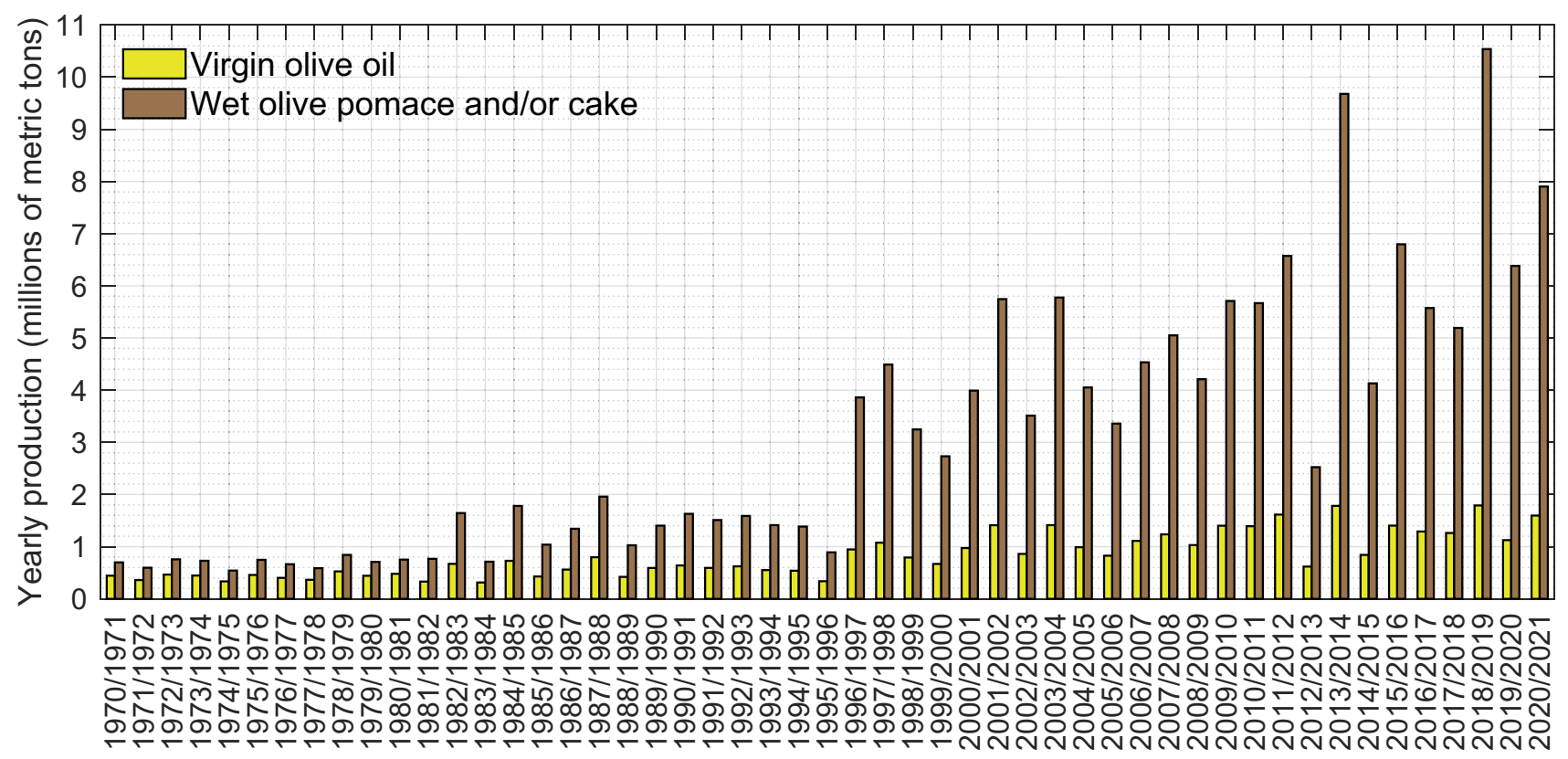

Fig. 1 Yearly production of virgin olive oil and wet olive pomace and/or cake in Spain since 1970

The performance of downdraft gasifiers coupled to microturbines has already been addressed in a number of works [13-24], and allows the generation of electric power for selfconsumption on a distributed scale. However, so far, it is not known of a previous work aimed at developing an integrated gasification process for simultaneously generating electric power and drying wet olive pomace at an olive oil mill. Despite their lower net electrical efficiency, microturbines were chosen over spark-ignition engines as power generation unit due to their greater availability of thermal energy in the exhaust gases [25-27]. An effective use of the thermal energy contained in the exhaust gases for the drying process of wet olive pomace can significantly improve microturbine system economics. Although microturbines are more expensive than traditional gas engines, their maintenance requirements are much less strict [26], as a result of their compactness and fewer moving parts [27], with maintenance intervals ranging from 5000 to $8000 \mathrm{~h}$ [28]. Additionally, the emissions of air pollutants such as carbon monoxide, unburned hydrocarbons and nitrogen oxides in the exhaust gases from microturbines are considerably lower than those of a gas engine of similar size, operating on the same mass flow rate of producer gas [16].

\section{Plant description and process modeling}

A schematic process flow diagram of the integrated gasification plant is presented in Fig. 2. The proposed plant consists of a pelletizing machine or pelletizer, a downdraft fixed bed gasifier fueled with dried olive pomace pellets, a producer gas cooling and cleaning unit, a microturbine for electric power generation and a co-current flow rotary drum dryer for drying wet olive pomace with the hot exhaust gases leaving the microturbine. For distributed power generation, air is preferred over pure oxygen as gasifying agent. Although the energy density of the gaseous product increases significantly in case of substituting air with oxygen, an air separation unit is generally not considered for small-scale applications, because of the extremely high capital and operation costs offsetting any advantage $[11,14,29]$. The choice of a downdraft fixed bed gasifier is justified for the following reasons:

- Compared to fluidized bed and entrained flow gasifiers, fixed bed gasifiers are fairly simpler reactors and involve a considerably lower investment cost.

- Downdraft gasifiers are generally limited to low thermal input $\left(<1 \mathrm{MW}_{\mathrm{th}}\right)$ and small-scale electric power generation [11], which is enough for electric self-sufficiency in most olive oil mills.

- As opposed to updraft gasifiers, a downdraft reactor configuration leads to a cleaner and yet moderately energydense producer gas $\left(\mathrm{LHV}=4-7 \mathrm{MJ} / \mathrm{Nm}^{3}\right)$ with a substantially lower tar content $\left(<3 \mathrm{~g} / \mathrm{Nm}^{3}\right)[11,12]$ and thus, more convenient for being supplied to microturbines after a mild cleaning stage. In fact, among all types of gasifiers, downdraft gasifiers have the lowest tar production rate, with an average value of around $1 \mathrm{~g} / \mathrm{Nm}^{3}$ [11]. 


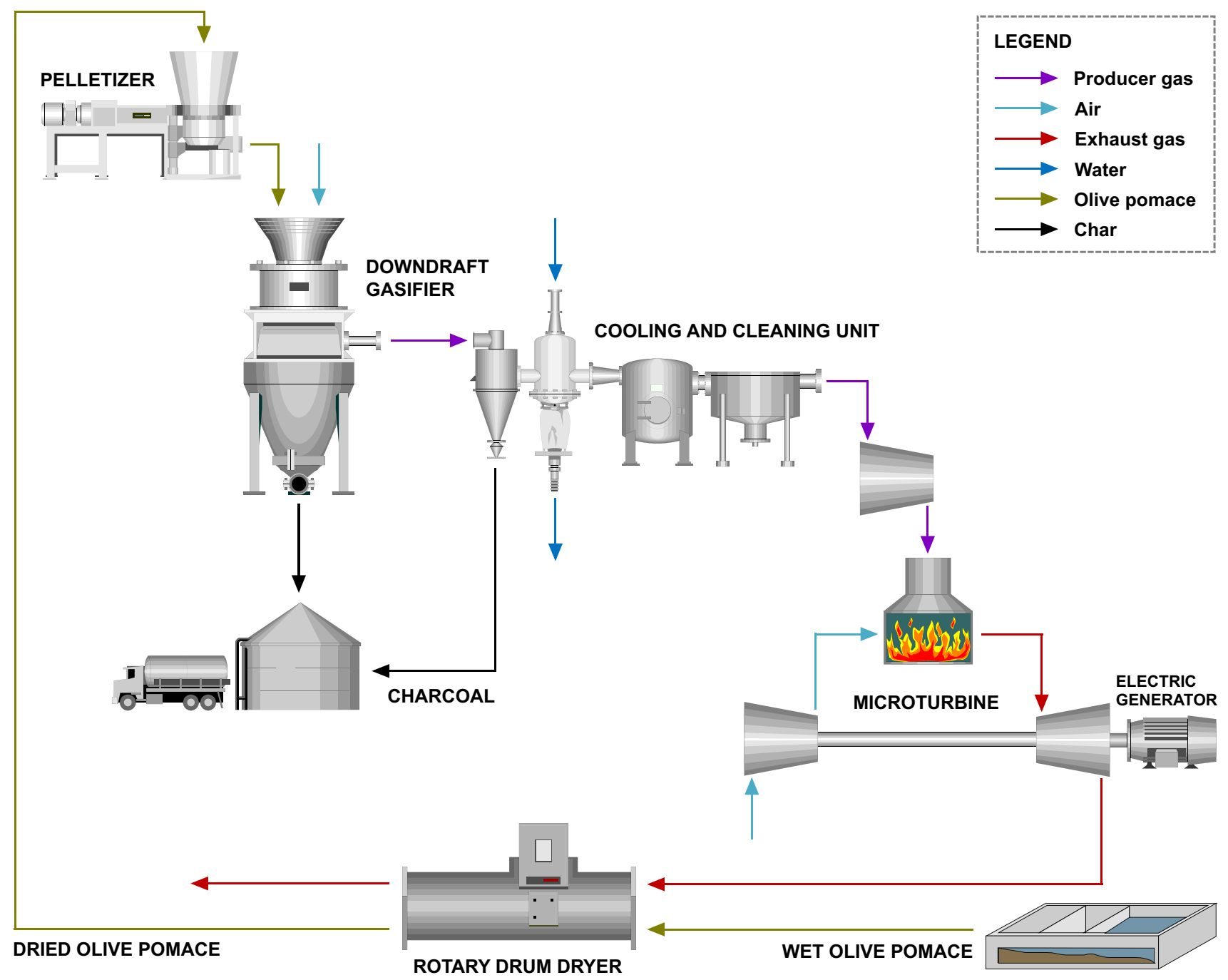

Fig. 2 Design process flow diagram of the integrated gasification plant

Accordingly, a simpler and less robust gas conditioning unit with lower energy consumption is required due to the lower concentration of tar in the producer gas.

- Fixed bed gasifiers are more suitable for coarse and nonfine particles $(3-51 \mathrm{~mm})$. Fine particles in downdraft gasifiers favor the formation of ash clinkers [30], which disturb the optimal flow in the gasifier bed, leading to pressure drop problems, low temperatures in the reduction zone and unstable operation. Therefore, the dried olive pomace must be pelletized in advance.

A large part of the particulate matter in the producer gas from the gasifier is separated in a cyclone. The hot producer gas is then sharply cooled down in a Venturi scrubber by spraying a pressurized water jet that also removes tars and inorganic impurities such as ammonia and alkali compounds (which dissolve readily in water). To conclude the cleaning stage, a series of filters eliminate mist and the remaining contaminants formed when vapors are cooled below their dew point, ensuring a suitable composition of the producer gas before entering the power generation unit. The clean producer gas is subsequently compressed and supplied to a microturbine in order to generate electric power. Finally, the hot exhaust gases discharged from the microturbine are used for drying wet olive pomace in a co-current flow rotary drum dryer, allowing a self-sufficient operation of the integrated gasification plant.

The integrated gasification plant for power generation and drying of olive pomace was implemented and modeled in Aspen Plus, a widely used process simulator in many research areas. Aspen Plus was chosen over other steady state process simulators because it has an extensive database of physicochemical properties and allows great flexibility in handling solids and non-conventional materials, as well as the option to insert customized statements in Fortran code. The enthalpy and density properties of non-conventional 
compounds (pomace and ashes) were estimated from the proximate, ultimate and sulfur analyses by means of the HCOALGEN and DCOALIGT methods [31]. Both models were originally developed for coal but are experimentally validated for biomass with a good approximation. The HCOALGEN method includes different empirical correlations to estimate heat of combustion, enthalpy of formation and specific heat; whereas the DCOALIGT method is based on the empirical correlations from the Institute of Gas Technology (IGT) to estimate density. The most usual physical property methods reported in the literature for modeling gasification processes are PR-BM and RKS-BM [18, 19, 24, 32-35], both providing comparable results [36]. The PengRobinson cubic equation of state with Boston-Mathias alpha function (PR-BM) was used to estimate all the thermodynamic properties of the conventional components involved in the integrated process. The stream class was defined as MCINCPSD, since there were both conventional and nonconventional streams with solid particles in the process [33, 37, 38]. The following general model assumptions were made in the Aspen Plus process simulations:

- The integrated gasification plant is operating under steady-state conditions within a zero-dimensional and time independent approach where hydrodynamic effects are disregarded [14, 17-19, 24, 33-35, 37-39].

- Heat losses to the surrounding environment and pressure drops across all unit operations are neglected [19, 24, 32-35, 37-39].

- All chemical reactions reach thermodynamic equilibrium conditions and reaction kinetics are not considered [14, 17-19, 24, 33-35, 37-39].
- Environment and reference state definition according to IUPAC Standard Ambient Temperature and Pressure (SATP), namely, $T_{0}=25^{\circ} \mathrm{C}$ and $p_{0}=1 \mathrm{bar}$.

Figure 3 displays the process flowsheet of the integrated plant for power generation and drying of wet pomace in Aspen Plus. It was divided into four distinguishable subsystems: gasification, gas cooling and cleaning, electric power generation and drying of wet pomace. The detailed features of each subsystem are described hereinafter.

\subsection{Gasification}

The gasification process was modeled assuming a downdraft gasifier under autothermal operation, which means that the feedstock reacts with the gasifying agent and produces enough heat to sustain the high temperatures required for the endothermic reactions to occur. The main simplifications in the gasification process simulations are listed below:

- The residence time of the reactants is supposed to be long enough to reach chemical equilibrium [38]. Thermodynamic equilibrium models have been widely used for predicting the final composition of the producer gas in fixed bed reactors, especially in downdraft gasifiers. In practice, the residence time of the reactants is generally not long enough to attain a complete equilibrium. However, downdraft gasifiers are regarded to usually operate very close to equilibrium conditions [40], due to the high temperatures reached and the sufficiently long gas residence time in the reaction zone.

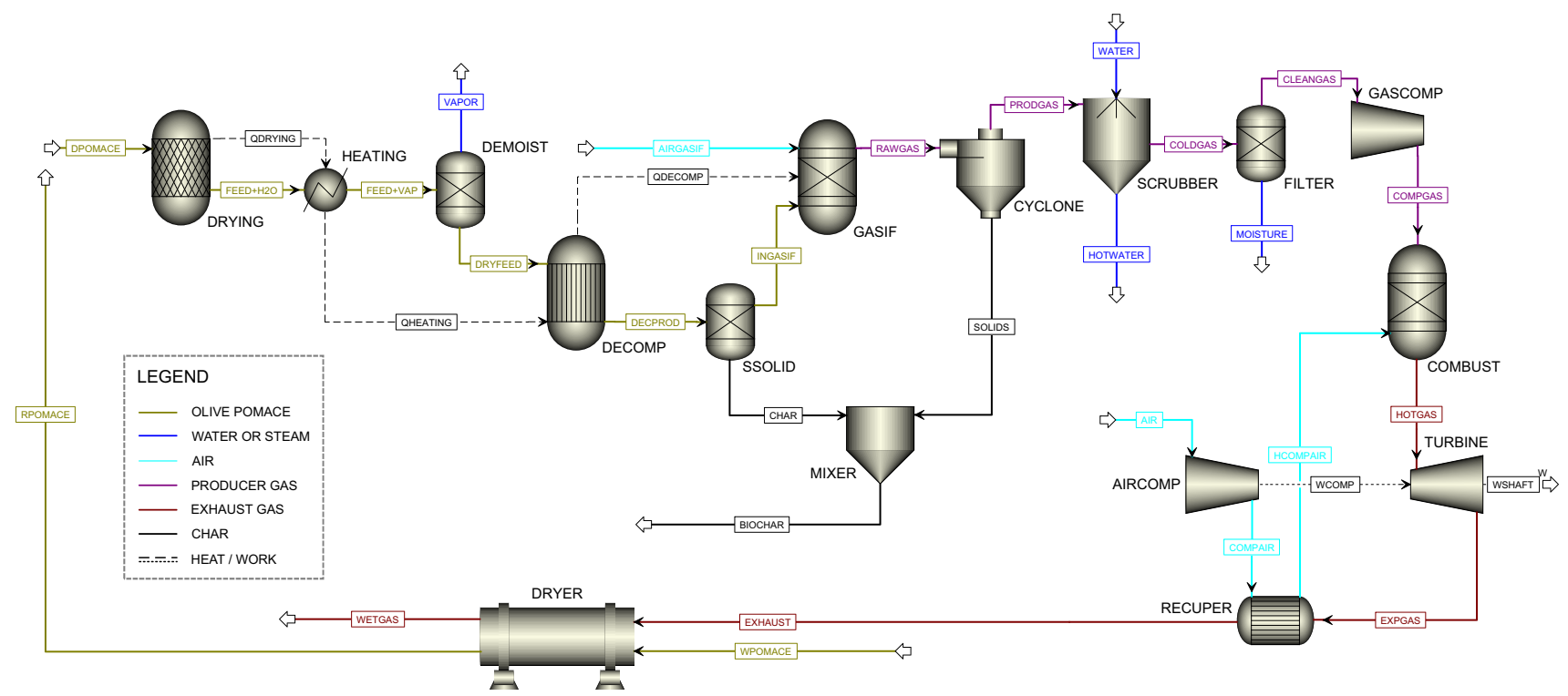

Fig. 3 Process simulation layout of the integrated plant for power generation and drying of wet pomace in Aspen Plus 
- The gasifying agent is humid atmospheric air at standard ambient conditions with the following molar composition: $20.75 \% \mathrm{O}_{2}, 77.29 \% \mathrm{~N}_{2}, 0.92 \% \mathrm{Ar}, 0.03 \% \mathrm{CO}_{2}$ and $1.01 \% \mathrm{H}_{2} \mathrm{O}$ (relative humidity is $60 \%$ ) [ 41 ].

- The carbon conversion efficiency is $95 \%$. Therefore, it is assumed that $5 \%$ of the carbon content in the feedstock remains unconverted and gets removed from the bottom of the gasifier together with ash [14, 17, 42, 43]. As a result, the carbonaceous residue discharged from the gasifier (char) is only made up of carbon and ash [38].

- Estimating the yield of tar is a challenge through a thermodynamic equilibrium model, because tar is typically a non-equilibrium product $[39,44]$. Tar production rate depends on reaction temperature, relative amount of oxygen and catalyst, if used [45]. Both yield and concentration of tar in the producer gas can be minimized by controlling the flow rate of air into the gasifier $[11,17]$. Catalysts can also facilitate tar reduction reactions either in the gasifier or downstream in a secondary reactor. Some catalysts that have proven effective in tar reduction are dolomite, alkali metal, nickel, olivine and char [11]. In accordance with other works in the scientific literature, predictions of tar yield in thermodynamic equilibrium models are mostly empirical, regardless of the actual operating conditions of the gasifier [46]. In these models, tar is often not included in thermodynamic equilibrium calculations and modeled as an inert compound (i.e., benzene, phenol and/or naphthalene) throughout the gasification process, where tar cracking and tar reduction reactions are not considered [14, 17, 39, 43, 44]. Thus, in order to reduce the complexity of the present model, tar formation was disregarded, since downdraft gasifiers are recognized for their very low tar content in the producer gas $\left(<3 \mathrm{~g} / \mathrm{Nm}^{3}\right)[11,12,24,32-35,37,38,42,44]$.

- The reaction temperature must be above $700{ }^{\circ} \mathrm{C}$, in order to achieve high carbon conversion efficiency and reduce tar formation [47]. Reaction temperatures above $800{ }^{\circ} \mathrm{C}$ in downdraft gasifiers are regarded to approach the equilibrium conditions with sufficient accuracy for thermodynamic considerations $[14,24$, $39,42,48]$.

- All nitrogen content in the feedstock is converted to either nitrogen $\left(\mathrm{N}_{2}\right)$ or ammonia $\left(\mathrm{NH}_{3}\right)$, and all sulfur content in the feedstock is converted to hydrogen sulfide $\left(\mathrm{H}_{2} \mathrm{~S}\right)[37,49]$. Thus, it is assumed that air pollutants such as nitrogen oxides $\left(\mathrm{NO}_{\mathrm{X}}\right)$, sulfur oxides $\left(\mathrm{SO}_{\mathrm{X}}\right)$, carbonyl sulfide (COS), carbon disulfide $\left(\mathrm{CS}_{2}\right)$ or hydrogen cyanide $(\mathrm{HCN})$ are not produced in the gasification process $[38,44]$. In a real gasification plant, nitrogen mostly appears as $\mathrm{N}_{2}$, with minor amounts of $\mathrm{NH}_{3}$ and $\mathrm{HCN}$ [50], and about $93-96 \%$ of the sulfur appears as $\mathrm{H}_{2} \mathrm{~S}$, the remaining as COS, which are relatively easily removed in the producer gas cleaning stage [11].
In Aspen Plus, there is not a specific block able to represent the gasification process; hence, a combination of several blocks is necessary for modeling the downdraft gasifier [39]. The gasification process shown in Fig. 3 was considered to be comprised of three stages: drying, pyrolysis and gasification. The gasification stage models the partial oxidation and reduction reactions.

The downdraft gasifier is supplied with dried olive pomace pellets at standard ambient conditions. Accordingly, the feedstock to the gasifier was defined as the non-conventional solid stream DPOMACE in terms of the proximate and ultimate analyses reported in Table 1, with an initial moisture content equal to $12.5 \%$ (wet basis). In the first stage of the gasification process, the moisture content of the feedstock is removed in block DRYING. The stoichiometric reactor (RStoic) was used to model the evaporation of moisture by calling an external Fortran subroutine [24, 32, 33]. The yield of water is given by the moisture content in the proximate analysis of the solid stream DPOMACE, which is evaporated in block HEATING and then separated in block DEMOIST through split fractionation of the components by using a separator (Sep). The dry pomace is placed into the next stage for decomposition after having already been separated from the evaporated moisture, which was drained out from the process. The heat of reaction associated with the drying stage was passed by a heat stream into block DECOMP, a non-stoichiometric yield reactor (RYield) wherein decomposition occurs [32].

In the pyrolysis stage, block DECOMP was used to convert the dry olive pomace into its constituent elements by specifying the yield distribution according to its ultimate analysis $[32,33,38]$. This function was performed through a user-programmed external Fortran statement. Char formation was modeled in block SSOLID by separating a small fraction (5\%) of carbon from the stream DECPROD as unconverted carbon, together with ash. The rest of the solid carbon together with the yield of volatiles make up the stream INGASIF, which proceeds to the last stage of the gasification process. The enthalpy of the outlet stream DECPROD was not equal to the enthalpy of the stream DRYFEED due to break up of chemical bonds. Therefore, the heat of reaction originated in the pyrolysis stage was transferred by a heat stream from block DECOMP into the next stage to replenish the difference in enthalpy [32, 35, 37].

The last stage of the gasification process models the partial combustion (oxidation) and gasification (reduction) reactions using a thermodynamic equilibrium model based on Gibbs free energy minimization, the formulation of which is detailed in $[38,48]$. At thermodynamic equilibrium, the system is considered to be at its most stable composition, which means that the entropy of system is maximized, while its Gibbs free energy is minimized. This modeling approach 
is known as non-stoichiometric, because it is needless to specify any possible chemical reactions taking place. The only input to be specified is the elemental composition or ultimate analysis of the feedstock to be processed [32]. Nonstoichiometric models are particularly suitable when all the possible reactions that can occur are unknown, as is the case of gasification. Hence, they are widely applied in the scientific literature. Although thermodynamic equilibrium may not be completely attained within the gasifier, equilibrium models provide a reasonable prediction for the final composition of the producer gas. The Gibbs free energy minimization model is implemented in block GASIF of Fig. 3 by means of the multiphase equilibrium reactor (RGibbs) that assumes a complete chemical equilibrium. In this block, ambient air is introduced as gasifying agent through the stream AIRGASIF, together with the yield distribution from stream INGASIF, due to the inability of the Gibbs reactor to manage non-conventional components such as olive pomace.

The gasification process is governed by the air-fuel equivalence ratio $(\lambda)$, which is defined as the actual oxidizer-fuel ratio supplied to the downdraft gasifier in relation to the oxidizer-fuel ratio required for stoichiometric combustion [14].

$\lambda=\frac{\left(\frac{\dot{m}_{\mathrm{O}_{2}}}{\dot{m}_{\text {fuel }}}\right)_{\text {actual }}}{\left(\frac{\dot{m}_{\mathrm{O}_{2}}}{\dot{m}_{\text {fuel }}}\right)_{\text {stoich }}}$

For a given flow rate of fuel into the downdraft gasifier,

$\lambda=\frac{\left(\frac{\dot{m}_{\mathrm{O}_{2}}}{\dot{m}_{\text {fuel }}}\right)_{\text {actual }}}{\left(\frac{\dot{m}_{\mathrm{O}_{2}}}{\dot{m}_{\text {fuel }}}\right)_{\text {stoich }}}=\frac{\left(\dot{\mathrm{O}}_{\mathrm{O}_{2}}\right)_{\text {actual }}}{\left(\dot{n}_{\mathrm{O}_{2}}\right)_{\text {stoich }}}=\frac{y_{\mathrm{O}_{2}} \dot{n}_{\text {air }}}{\eta_{c c} \dot{n}_{\mathrm{C}}+\frac{1}{4} \dot{n}_{\mathrm{H}}-\frac{1}{2} \dot{n}_{\mathrm{O}}}$

where $\dot{n}_{\text {air }}$ is the mole flow rate of air as gasifying agent, $y_{\mathrm{O}_{2}}$ is the mole fraction of oxygen in the air, $\eta_{c c}$ is the carbon conversion efficiency and $\dot{n}_{\mathrm{C}}, \dot{n}_{\mathrm{H}}$, and $\dot{n}_{\mathrm{O}}$ are the mole flow rates of carbon, hydrogen and oxygen from the ultimate analysis of the feedstock to the gasification process [47]. A mixture with $\lambda=1$ is at stoichiometry, for fuel-rich mixtures $\lambda<1$ and for fuel-lean mixtures $\lambda>1$. Hence, complete combustion occurs at an equivalence ratio of 1 , so that most carbon in the feedstock is oxidized to provide the maximum concentration of carbon dioxide in the product stream [51]. The expression in Eq. (2) is derived from the general complete combustion reaction of a solid fuel containing carbon, hydrogen and oxygen.

$\mathrm{C}_{x} \mathrm{H}_{y} \mathrm{O}_{z}+\left(x+\frac{y}{4}-\frac{z}{2}\right) \mathrm{O}_{2} \rightarrow x \mathrm{CO}_{2}+\frac{y}{2} \mathrm{H}_{2} \mathrm{O}$

The mole flow rate of air in the stream AIRGASIF supplied to the multiphase equilibrium reactor in block GASIF was controlled by a user-programmed external subroutine in
Fortran code according to Eq. (2). The air-fuel equivalence ratio was then adjusted within the usual range in downdraft gasifiers $(\lambda=0.20-0.45)[35,37,38,52,53]$. The reaction temperature inside the gasifier was controlled by varying the equivalence ratio.

The gasification efficiency right at the outlet of the downdraft gasifier is typically termed as hot gas efficiency $\left(\eta_{h g}\right)$. By taking the sensible heat of the hot gas into account, it can be defined as follows:

$\eta_{h g}=\frac{\dot{m}_{h g}\left(\mathrm{LHV}_{h g}+c_{p, h g}\left(T_{h g}-T_{0}\right)\right)}{\dot{m}_{d p} \mathrm{LHV}_{d p}}$

where $\dot{m}_{h g}$ and $\dot{m}_{d p}$ represent the mass flow rates of hot producer gas and dried olive pomace pellets, respectively. The hot gas efficiency only assumes the heating of the unconverted char to be a loss [11].

\subsection{Producer gas cooling and cleaning}

The direct use of the producer gas from the downdraft gasifier with traces of tar, ash, moisture and other inorganic impurities is not feasible in microturbines, since it compromises their structural integrity. These undesired constituents, if not removed, can cause severe damages and corrosion problems to all mechanical equipment [14]. Microturbines are particularly sensitive machines with stringent restrictions on the cleanliness of the producer gas in order to avoid damage to the turbine blades (such as erosion, incrustation or corrosion) and blockage of filters and fuel injectors. Particulate and tar concentrations in the producer gas should therefore be below $5 \mathrm{mg} / \mathrm{Nm}^{3}$ [11]. For this reason, a producer gas cooling and cleaning unit must be included downstream of the gasifier, consisting of a cyclone, a Venturi scrubber and a series of filters.

As shown in Fig. 3, the raw producer gas at high temperature from the downdraft gasifier, defined by the stream RAWGAS, was placed into block CYCLONE, where the solid particulate matter is partially removed. The separator SSplit was used to model the cyclone. The cyclone collection efficiency for different particle diameters and gas velocities typically ranges from 70 to $100 \%$ [54]. The average value of $85 \%$ was used in this work [37]. The gaseous stream PRODGAS from the cyclone was transferred to block SCRUBBER, modeled as a Venturi scrubber gas-solid separator (VScrub). The scrubber is supplied with the hot producer gas and fresh water at standard ambient conditions, achieving drastic gas cooling and mass transfer of tar and inorganic impurities such as ammonia and hydrogen sulfide from the producer gas to the water stream [14, 17]. Rapid cooling in the scrubber also causes oversaturation of vapors and formation of mist in the cold producer gas of stream COLDGAS. This undesired mist is composed of small droplets of liquid 
water and tar particles, which, if not removed from the producer gas, would lead to significant damages downstream toward the power generation unit and a lower overall efficiency. Therefore, tar and water mist, which for simplicity is considered composed only of water [35], must be separated from the cold producer gas in block FILTER, defined as a gas-liquid separator (Sep) module [35], producing the almost mist-free stream CLEANGAS. As tar formation in the downdraft gasifier was disregarded in order to simplify the model, the gas conditioning unit is assumed to be able to comply with the rather strict requirements on the cleanliness of the producer gas for being supplied to the microturbine.

The gasification efficiency after the gas cleaning and cooling stage, commonly known as cold gas efficiency $\left(\eta_{c g}\right)$ [11], was determined as follows:

$\eta_{c g}=\frac{\dot{m}_{c g} \mathrm{LHV}_{c g}}{\dot{m}_{d p} \mathrm{LHV}_{d p}}$

where $\dot{m}_{c g}$ and $\dot{m}_{d p}$ represent the mass flow rates of clean producer gas and dried olive pomace pellets, respectively.

\subsection{Microturbine}

A microturbine fueled with the clean producer gas from gasification was proposed for electric power generation on a distributed scale. The operating principle of microturbines is based on the recuperated Brayton cycle [25]. Current microturbines can use either liquid or gaseous fuels, but they have strict requirements regarding the quality of the exhaust gases that are used to drive the turbine rotor, being intolerant to solid particles, droplets and other impurities [14, 18].

The microturbine power generation unit displayed in Fig. 3 consists of various unit operation blocks: fuel booster compressor, air compressor, recuperator, combustion chamber and expansion turbine [25]. Since each component is separate and has a different task, they can be designed and tested individually. The fuel booster compressor in block GASCOMP brings the clean producer gas from the previous stage, defined as the stream CLEANGAS, to the operating pressure of the combustion chamber, resulting in stream COMPGAS. Likewise, an ambient air stream is compressed in block AIRCOMP to the operating pressure of the combustion chamber and preheated in block RECUPER with the hot exhaust gases from the turbine discharge, producing the stream HCOMPAIR. The flow rate of the ambient air stream was controlled by a user-programmed external Fortran statement. Both pressurized streams are mixed in block COMBUST, modeled as a multiphase equilibrium reactor (RGibbs), where complete combustion of the producer gas with excess air occurs at constant pressure. The equilibrium model assumes that the residence time in the combustor is sufficient to achieve complete combustion. The resulting gas stream from the combustor (HOTGAS) at high pressure and temperature then expands in the microturbine to atmospheric pressure while producing mechanical power, which can later be transformed into electric power by coupling an electric generator. The exhaust gases discharged from the microturbine at ambient pressure and yet a relatively high temperature are designated as stream EXPGAS. The electrical efficiency of the power generation unit is moderately increased with a recuperator (block RECUPER), which is a gas-to-air counter-current heat exchanger (HeatX) located between the compressor and the combustor, using excess heat from the exhaust gases leaving the microturbine to preheat air for the combustor. Finally, the stream EXHAUST from the recuperator is still at temperatures close to $300{ }^{\circ} \mathrm{C}$ and will be used in the last stage of the integrated process for drying wet olive pomace in a co-current flow rotary drum dryer.

Microturbines are generally designed and commercialized for fuels with high energy content such as natural gas, diesel or biogas. However, there are a number of simulations and experimental works related to the use of the producer gas from gasification as fuel for microturbines [14-23]. Typical values for performance parameters used in the system calculations are reported in Table 2 [14, 17-19].

In the gas turbine industry, the fuel-air equivalence ratio $(\varphi)$ is typically used when discussing the mixture of air and fuel. It refers to the amount of excess air present in the combustion chamber in relation to the amount of air required for stoichiometric combustion, with values less than 1 indicating presence of excess air and greater than 1 indicating excess fuel. It is well established that emissions of nitrogen oxides increase with temperature. Current low-emission combustion systems tend to operate with a high amount of excess air (i.e., equivalence ratios well below 1, down to about $0.1-0.2$ in recuperated cycle configurations [55, 56]) to help minimize combustion temperatures responsible for high formation rates of nitrogen oxides. Furthermore, if turbine inlet temperatures rise above $900{ }^{\circ} \mathrm{C}$, costly materials and complex cooling systems for the turbine blades

Table 2 Microturbine simulation specifications based on typical performance parameters

\begin{tabular}{llll}
\hline Subsystem & Parameter & Value & Unit \\
\hline Gas turbine & Isentropic efficiency $\left(\eta_{i}\right)$ & 84.1 & $\%$ \\
& Mechanical efficiency $\left(\eta_{m}\right)$ & 97.0 & $\%$ \\
& Turbine inlet temperature $(T I T)$ & $750-900$ & ${ }^{\circ} \mathrm{C}$ \\
& Turbine exhaust temperature & $\sim 300$ & ${ }^{\circ} \mathrm{C}$ \\
Compressors & Isentropic efficiency $\left(\eta_{i}\right)$ & 79.6 & $\%$ \\
& Mechanical efficiency $\left(\eta_{m}\right)$ & 97.0 & $\%$ \\
Generator & Electricity generation efficiency $\left(\eta_{g e n}\right)$ & 90.0 & $\%$ \\
& DC/AC conversion efficiency $\left(\eta_{D C / A C}\right)$ & 97.0 & $\%$ \\
\hline
\end{tabular}


are required, thereby increasing the capital expenditure and maintenance costs $[14,17]$. The fuel-air equivalence ratio is related to the air-fuel equivalence ratio (defined previously) as follows:

$\varphi=\frac{1}{\lambda}=\frac{\left(\frac{\dot{m}_{\text {futel }}}{\dot{m}_{\mathrm{O}_{2}}}\right)_{\text {actual }}}{\left(\frac{\dot{m}_{\text {futel }}}{\dot{m}_{\mathrm{O}_{2}}}\right)_{\text {stoich }}}$

In this work, the airflow rate was selected in order to reach a minimum value for $\lambda$ equal to 6 , which means that the actual oxidizer-fuel ratio is at least six times the stoichiometric oxidizer-fuel ratio $(\lambda \geq 6)[13,14,17]$. The mass flow rate of air required for stoichiometric combustion was calculated by means of the main oxidation reactions that occur in the microturbine combustion chamber:

$2 \mathrm{CO}+\mathrm{O}_{2} \rightarrow 2 \mathrm{CO}_{2}$

$2 \mathrm{H}_{2}+\mathrm{O}_{2} \rightarrow 2 \mathrm{H}_{2} \mathrm{O}$

$\mathrm{CH}_{4}+2 \mathrm{O}_{2} \rightarrow \mathrm{CO}_{2}+2 \mathrm{H}_{2} \mathrm{O}$

The net electric power $\left(P_{e}\right)$ and net electrical efficiency $\left(\eta_{e}\right)$ of the gasifier-microturbine system are given by the following equations:

$P_{e}=\eta_{D C / A C} \eta_{g e n}\left(P_{\text {turb }}-P_{\text {comp }}\right)$

$\eta_{e}=\frac{P_{e}}{\dot{m}_{d p} \mathrm{LHV}_{d p}}$

where $P_{\text {turb }}$ and $P_{\text {comp }}$ represent the turbine and compressors mechanical power, respectively, $\eta_{\text {gen }}$ is the generator electrical efficiency and $\eta_{D C / A C}$ is the DC/AC power conversion efficiency $[14,17]$. The main parameters affecting the net electrical efficiency are the compressor pressure ratio $(\Pi)$, defined as the ratio of the stagnation pressure at the front and rear of the microturbine compressor, and the turbine inlet temperature (TIT). However, both parameters can only be increased up to certain limits, dictated by material tolerances and the cost of manufacturing.

\subsection{Rotary drum dryer}

The drying process of wet olive pomace consists of a rotary drum dryer and a source of thermal energy in the form of hot exhaust gases discharged from the microturbine, as shown in Fig. 3. The convective dryer models the evaporation of moisture from the wet solid feedstock into the exhaust gas stream with the aim to reduce the moisture content of the feedstock to an acceptable level. This evaporation process requires a large amount of energy because moisture has a high enthalpy of vaporization [57]. In directly heated dryers, the amount of water evaporating from the solid phase corresponds to the increase in humidity of the drying gas [58],

$\dot{m}_{s}\left(X_{1}-X_{2}\right)=\dot{m}_{e g}\left(Y_{2}-Y_{1}\right)$

where $X_{1}$ and $X_{2}$ represent the moisture contents (dry basis) of solids at the dryer inlet and outlet, respectively; $Y_{1}$ and $Y_{2}$ are the inlet and outlet gas humidity contents, respectively; and $\dot{m}_{e g}$ is the mass flow rate of drying exhaust gas. The enthalpy balance of the convective dryer is given by the following equation:

$\dot{m}_{s}\left(h_{s, 1}+X_{1} h_{w, 1}\right)+\dot{m}_{e g} h_{e g, 1}=\dot{m}_{s}\left(h_{s, 2}+X_{2} h_{w, 2}\right)+\dot{m}_{e g} h_{e g, 2}$

where $h_{s}, h_{w}$ and $h_{e g}$ are the specific enthalpies of dry solid, water and exhaust gas, respectively. Subscripts 1 and 2 indicate the dryer inlet and outlet, respectively.

Rotary drum dryers can be divided into co-current and counter-current types, depending on the flow direction of the drying gas. Although counter-current rotary drum dryers can lead to products with a lower moisture content, their risk of catching fire and releasing volatiles to the environment is substantially higher [59, 60]. Moreover, the vast majority of industrial rotary drum dryers operate in a co-current or parallel flow direction [61, 62]. Thus, a co-current rotary drum dryer was modeled in this work, where wet olive pomace with a high moisture content (65\%, wet basis) and the hot exhaust gases from the microturbine discharge flow through the dryer in a co-current flow direction. This immediately puts the wet olive pomace in contact with the hot drying gas, resulting in quick initial drying and rapid cooling of the drying gas. The inlet temperature of the drying gas was considered equal to the turbine exhaust temperature $\left(300^{\circ} \mathrm{C}\right)$. The residence time of the wet olive pomace was set so as not to exceed the average residence time of a typical rotary drum dryer of about $20 \mathrm{~min}$ [59, 61, 63]. The mass flow rate of wet pomace was adjusted in order to obtain a product with a moisture content of $12.5 \%$ (wet basis) at the dryer outlet.

A directly heated co-current flow rotary drum dryer operating in steady-state conditions with no heat loss was considered for the simulation. A convective solid dryer block was selected from the available solid unit operations in Aspen Plus. Drying kinetics data are essential in the sizing of industrial drying equipment. The convective dryer model in Aspen Plus is based on the dimensionless characteristic drying curves proposed by Van Meel [64, 65]. The parameters required for modeling the drying kinetics of wet olive pomace in Aspen Plus are the mass transfer coefficient $(\beta)$, the heat transfer coefficient $(\alpha)$, the critical moisture content $\left(X_{c}\right)$ of the feedstock, the equilibrium 
moisture content $\left(X_{e}\right)$ and the drying curve of a falling-rate drying period $[59,60,66]$. The kinetic data for drying of wet olive pomace were obtained from [9]. The mass and heat transfer coefficients were calculated from Eqs. 14 and 15. In order to calculate the Sherwood, Lewis, Schmidt and Reynolds numbers, the drying gas diffusivity $\left(\delta_{e g}\right)$, density $\left(\rho_{e g}\right)$ dynamic viscosity $\left(\mu_{e g}\right)$, specific heat $\left(c_{p, e g}\right)$ and thermal conductivity $\left(k_{e g}\right)$ were obtained by using the stream analysis of Aspen Plus. The diameter required to calculate the mass transfer coefficient and Reynolds number was replaced with Sauter mean diameter $\left(d_{32}\right)$ and the median particle diameter $\left(d_{m}\right)$ of wet olive pomace, respectively $[59,60]$. The velocity of the drying gas for calculation of heat and mass transfer coefficients (typical range from 0.5 to $2.5 \mathrm{~m} / \mathrm{s}$ ) was selected as the average value of $1.5 \mathrm{~m} / \mathrm{s}$ [59].

$$
\begin{aligned}
& \beta=\frac{\delta_{e g}}{d_{32}} \mathrm{Sh} \\
& \alpha=\rho_{e g} c_{p, e g} \beta \\
& \mathrm{Sh}=\sqrt{\mathrm{Sh}_{\text {laminar }}^{2}+\mathrm{Sh}_{\text {turbulent }}^{2}} \\
& \mathrm{Sh}_{\text {laminar }}=0.664 \sqrt{\operatorname{Re}} \sqrt[3]{\mathrm{Sc}}
\end{aligned}
$$

$\mathrm{Sh}_{\text {turbulent }}=\frac{0.037 \cdot \mathrm{Re}^{0.8} \mathrm{Sc}}{1+2.443 \cdot \mathrm{Re}^{-0.1}\left(S^{2} / 3-1\right)}$

$\operatorname{Re}=\frac{u_{e g} d_{m} \rho_{e g}}{\mu_{e g}}$

$\mathrm{Sc}=\frac{\mu_{e g}}{\delta_{e g} \rho_{e g}}$

$\mathrm{Le}=\frac{k_{e g}}{\delta_{e g} \rho_{e g} c_{p, e g}}$

There are different efficiency terms for rotary drum dryers reported in the literature such as drying thermal efficiency and drying energy efficiency [66]. The drying thermal efficiency $\left(\eta_{t h}\right)$ was calculated as the ratio of the energy used for the moisture evaporation to the total thermal energy input for drying. The drying energy efficiency $\left(\eta_{d r y}\right)$ was conveniently defined in this work as the ratio of the energy used for moisture evaporation to the energy content in the feedstock to the integrated gasification plant.
Finally, the overall efficiency of the integrated plant $\left(\eta_{o}\right)$ was determined as the ratio of the useful energy outputs (electrical energy and moisture evaporation) to the net energy input to the gasifier.

$\eta_{t h}=\frac{\dot{m}_{w} \Delta H_{v a p}}{\dot{m}_{e g} c_{p, e g}\left(T_{e g}-T_{0}\right)}$

$\eta_{d r y}=\frac{\dot{m}_{w} \Delta H_{v a p}}{\dot{m}_{d p} \mathrm{LHV}_{d p}}$

$\eta_{o}=\frac{\eta_{D C / A C} \eta_{g e n}\left(P_{t u r b}-P_{c o m p}\right)+\dot{m}_{w} \Delta H_{v a p}}{\dot{m}_{d p} \mathrm{LHV}_{d p}}$

\section{Results and discussion}

In this section, the results of the Aspen Plus simulations are presented and discussed in order to evaluate the performance of the proposed integrated plant operating in steady state with the assumptions cited in the previous section. All the unit operations and streams included in the process were sized considering that the downdraft gasifier is supplied with dried olive pomace pellets $(12.5 \%$ moisture content, wet basis) at a constant rate of $300 \mathrm{~kg} / \mathrm{h}$. A nominal electric power consumption of $33 \mathrm{~kW}_{\mathrm{e}}$ was assumed for pelletization of the dried olive pomace, as specified in the manufacturer's data sheet of an industrial pelletizer with a production capacity of $200-500 \mathrm{~kg} / \mathrm{h}$. Thus, the specific energy consumption for pelletization of $300 \mathrm{~kg} / \mathrm{h}$ of dried olive pomace is estimated at $0.11 \mathrm{kWh} / \mathrm{kg}$, which lies within the reported range of specific energy consumption for pelletization of biomass blends [67].

\subsection{Gasification}

The chemical composition and yield of producer gas in gasification processes are governed by a number of variables, such as the reaction temperature, the equivalence ratio and the physicochemical properties of the feedstock: proximate and ultimate composition, particle size distribution and moisture content. In autothermal gasifiers, the reaction temperature is a dependent variable of the relative amount of oxidizer or herein referred to as equivalence ratio. Therefore, both parameters have a combined influence on the composition and heating value of the producer gas. The effect of the air-fuel equivalence ratio $(\lambda)$ on the gasification temperature is illustrated in Fig. 4a). It can be observed that $\lambda$ must be at least 0.33 for the gasification temperature to reach $700{ }^{\circ} \mathrm{C}$, thereby ensuring a low tar content in the producer gas composition $\left(<3 \mathrm{~g} / \mathrm{Nm}^{3}\right)$. In 
a)

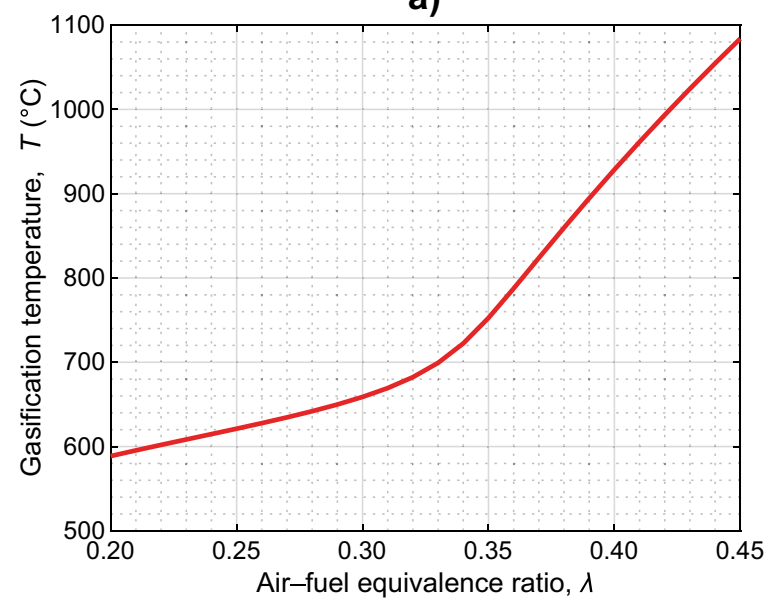

b)

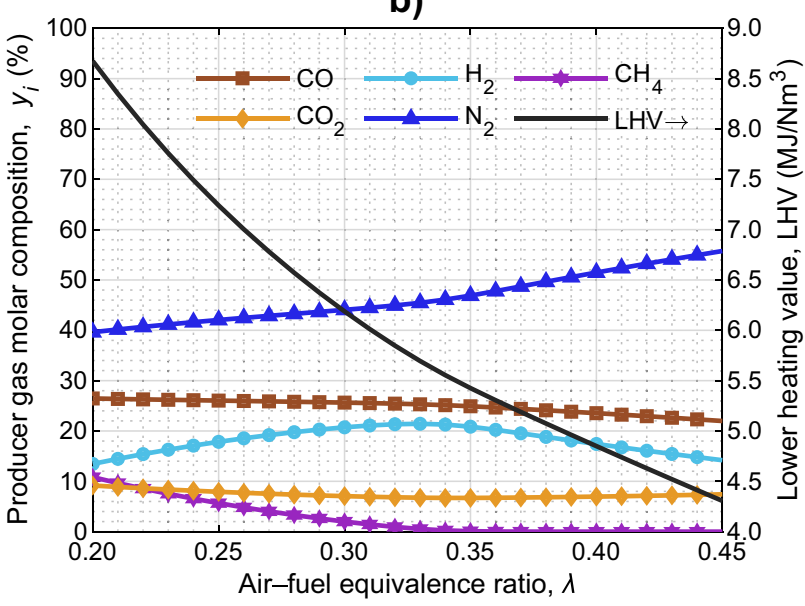

c)

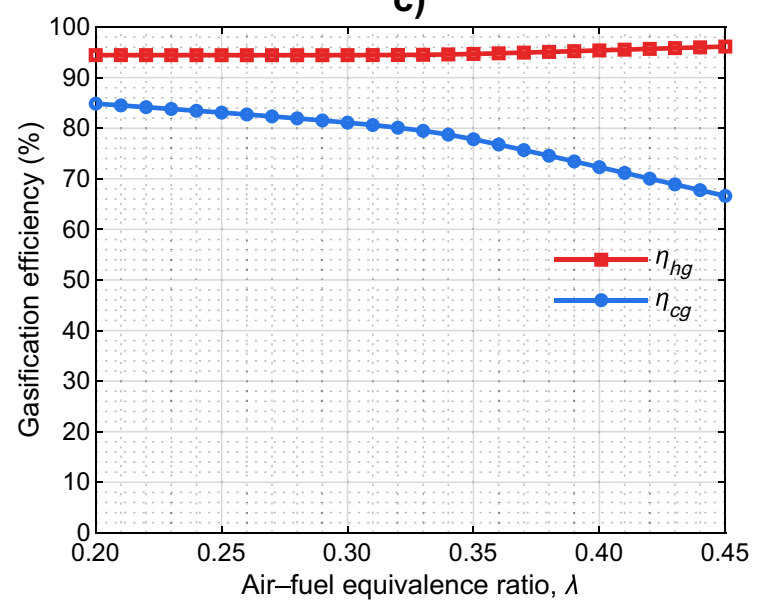

Fig. 4 Effect of the equivalence ratio on a) the gasification temperature, b) the composition and heating value of the clean producer gas, and c) the hot and cold gas efficiencies of the gasification process

addition, as mentioned earlier, the gasification temperature should be above $800^{\circ} \mathrm{C}$ in order to apply thermodynamic equilibrium models with sufficient accuracy [48]. A gasifier reaction temperature of $800{ }^{\circ} \mathrm{C}$ can be attained by setting the equivalence ratio at 0.363 .

Figure $4 \mathrm{~b}$ presents the molar composition and lower heating value of the cold producer gas (after passing through the cooling and cleaning units) on a dry basis as a function of the air-fuel equivalence ratio $(\lambda)$, which was varied over a range of values from 0.20 to 0.45 . Worthy of note is that thermodynamic equilibrium models can reasonably predict the producer gas composition assuming that a complete equilibrium is reached, which is certainly not the case for downdraft gasifiers operating at temperatures below $800{ }^{\circ} \mathrm{C}$ as a result of the slow reaction kinetics. Therefore, the producer gas composition and heating values shown in Fig. $4 \mathrm{~b}$ are those expected at thermodynamic equilibrium and do not apply for the downdraft gasifier of the present work operating at values of $\lambda$ below 0.33 . In other words, the smaller the air-fuel equivalence ratio, the lower is the gasification temperature and the further away are all the predicted performance parameters from the actual values.

As discussed above, higher values of $\lambda$ lead to higher gasification temperatures, which are conducive to products of endothermic reactions, according to Le Chatelier's principle. Hence, an increase in the gasification temperature typically leads to a producer gas with higher contents of hydrogen and carbon monoxide [32, 35, 37]. By contrast, the contents of carbon dioxide and methane follow an opposite trend with increasing gasification temperatures, as a result of the prevalence of steam reforming reaction over water gas shift forward reaction [24]. The concentration of methane is usually negligible in thermodynamic equilibrium models at temperatures above $800{ }^{\circ} \mathrm{C}$, because the methane formation reaction is exothermic [68]. In practice, however, the producer gas generally does not achieve complete equilibrium composition in downdraft gasifiers, as indicated by the presence of a higher methane content than predicted [37, 39]. Despite the favorable effects of higher temperatures toward the formation of products of endothermic reactions, Fig. $4 \mathrm{~b}$ shows that the growing availability of oxygen with increasing values of $\lambda$ ultimately results in lower contents of hydrogen and carbon monoxide in the producer gas due to the formation of water vapor and carbon dioxide [38]. Additionally, an increasing equivalence ratio leads to a larger presence of inert gases such as nitrogen and argon in the producer gas composition. The pronounced decline in the lower heating value of the cold producer gas is mostly explained by the nitrogen dilution effect and the reduction in the contents of carbon monoxide and hydrogen, which are increasingly oxidized to carbon dioxide and water vapor, respectively, as the equivalence ratio proceeds toward stoichiometric combustion.

The effect of the air-fuel equivalence ratio on the hot and cold producer gas efficiencies is shown in Fig. 4c. The 
steady decline in the cold gas efficiency $\left(\eta_{c g}\right)$ is justified by the drastic drop in the lower heating value of the clean producer gas with increasing values of $\lambda$, which is partially offset by the increasing flow rate of producer gas. By contrast, the hot gas efficiency $\left(\eta_{h g}\right)$ remains stable at about $95 \%$ because increasing values of $\lambda$ lead to higher temperatures of the producer gas. The increase in thermal energy of the producer gas is theoretically able to balance out the declining lower heating value $[41,69]$. Nevertheless, in practice, higher gasification temperatures also involve greater thermal losses to the environment as radiation and convection, leading to smaller hot gas efficiencies than those displayed in Fig. 4c.

The thermodynamic equilibrium model of the downdraft gasifier developed in the present work was validated by comparison of the current predictions with the experimental results of Jayah et al. [70]. This work has been widely used in the scientific literature for validation of thermodynamic equilibrium models of downdraft gasifiers [21, 32, 38, 39, $47,48,68]$. In their experiments, rubber wood was supplied to a downdraft gasifier at atmospheric pressure and a gasification temperature of $900{ }^{\circ} \mathrm{C}$ using air as gasifying agent. In order to validate the thermodynamic equilibrium modeling approach for the downdraft gasifier of the present work operating at temperatures above $800{ }^{\circ} \mathrm{C}$, three different air-fuel ratios were considered for comparison of the producer gas molar composition, namely 2.03, 2.20 and 2.37. Air-fuel ratios were simply defined as the mass flow rate ratio of air to fuel, regardless of combustion stoichiometry. As shown in Fig. 5, the predicted values for the molar fractions of the main species that constitute the producer gas using the thermodynamic equilibrium model implemented in Aspen Plus are mostly in good agreement with the experimental results of Jayah et al. [70]. As expected, major deviations are always obtained for the concentration of methane. The experimental values of methane concentration are in the range of $1.1-1.4 \%$, whereas the model predictions are very close to zero. As complete thermodynamic equilibrium is not attained in downdraft gasifiers, the measured concentration of methane cannot be explained based on a purely thermodynamic equilibrium model [48, 68]. However, the comparisons with experimental results reveal that the developed thermodynamic equilibrium model is sufficiently reliable for the purpose of the present work, since methane has the lowest concentration among the main species in the producer gas.

Hereinafter, a gasifier reaction temperature of $800{ }^{\circ} \mathrm{C}$ was considered by setting the air-fuel equivalence ratio at 0.363 , thereby ensuring sufficient accuracy in approaching equilibrium conditions in addition to a low tar content in the producer gas composition. Under such conditions, the yield of producer gas is $765 \mathrm{Nm}^{3} / \mathrm{h}$, with the following molar composition: $24.5 \% \mathrm{CO}, 20.0 \% \mathrm{H}_{2},<0.1 \% \mathrm{CH}_{4}, 6.7 \% \mathrm{CO}_{2}$, $48.2 \% \mathrm{~N}_{2}$ and $0.5 \%$ Ar. Consequently, the lower heating value of the producer gas is $5.25 \mathrm{MJ} / \mathrm{Nm}^{3}$, and the cold gas efficiency $\left(\eta_{c g}\right)$ is equal to $76.5 \%$.

\subsection{Microturbine}

The main performance parameters of the power generation unit, such as compressor pressure ratio, fuel-air equivalence ratio, turbine inlet temperature and net electrical efficiency, were evaluated in order to maximize the electric power generation. Figure 6 shows the dependence of the net electrical efficiency $\left(\eta_{e}\right)$ with the compressor pressure ratio $(\Pi)$ at different turbine inlet temperatures $\left(T I T=750{ }^{\circ} \mathrm{C}, 800{ }^{\circ} \mathrm{C}\right.$, $850^{\circ} \mathrm{C}$ and $900^{\circ} \mathrm{C}$ ). It can be observed that, for a particular turbine inlet temperature, the net electrical efficiency of the
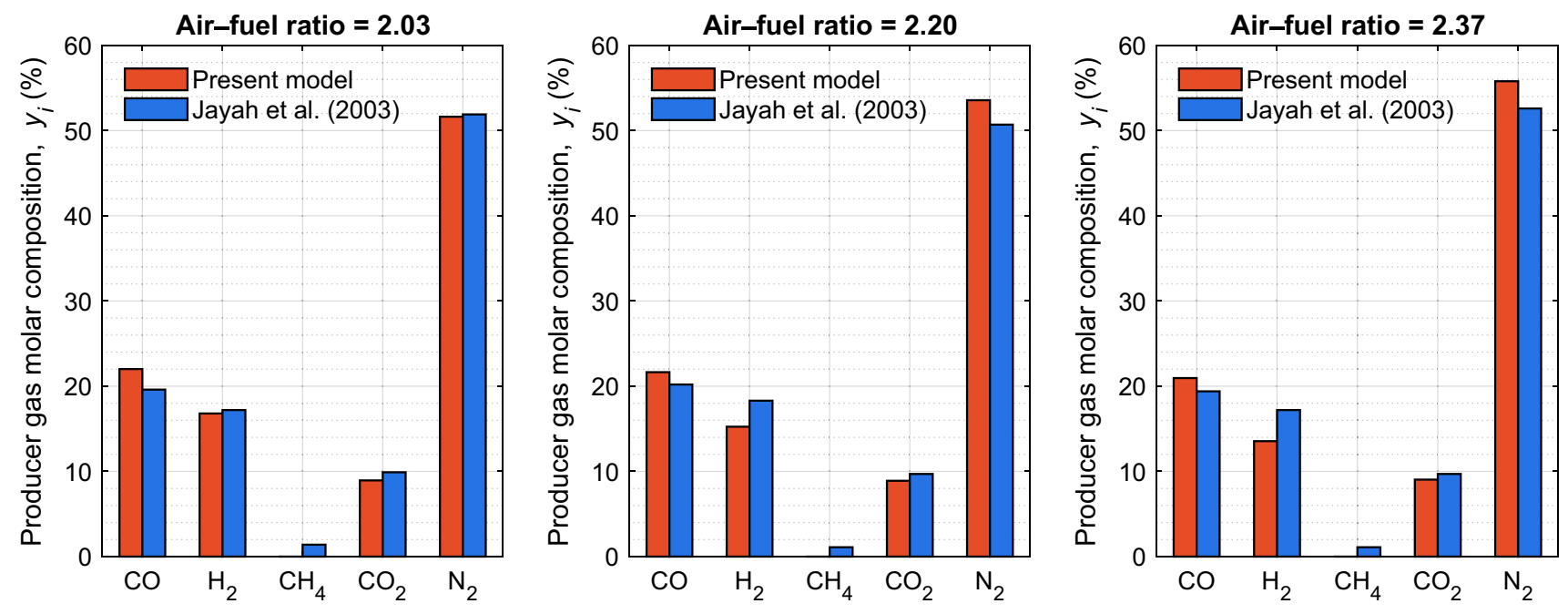

Fig. 5 Validation of the present gasification model with the experimental results of Jayah et al. [70] 


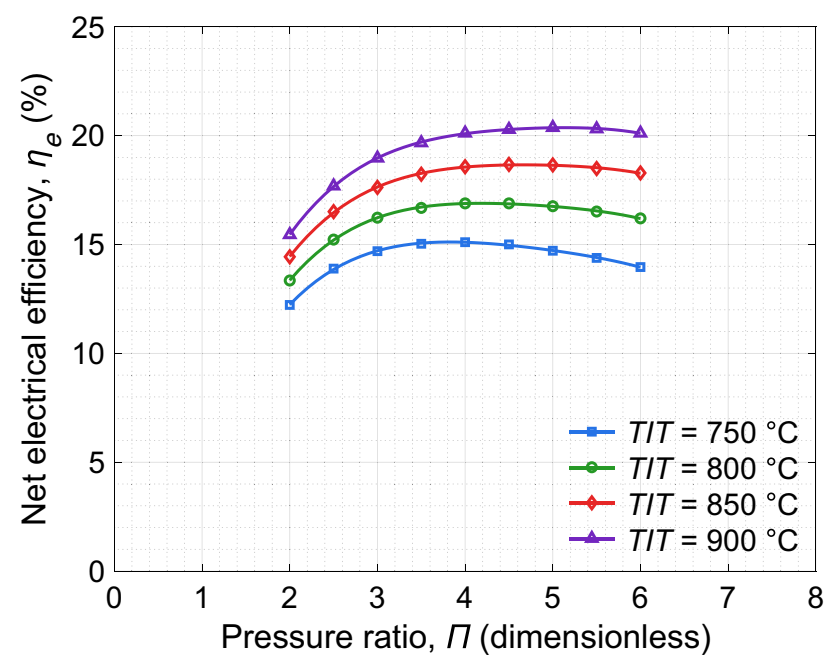

Fig. 6 Effect of the pressure ratio and turbine inlet temperature on the net electrical efficiency

gasifier-microturbine system first improves with increasing values of $\Pi$ up to a maximum value and then decreases with further increase of $\Pi$. This is because increasing values of $\Pi$ cause increments in the power generated by the microturbine and the power consumed by the compressor in the power generation unit. At lower values of $\Pi$, the increment of power generated by the turbine is leading, and thus, the net power increases. At higher values of $\Pi$, the increment of power consumed by the compressor is dominant, and hence, the net power decreases. Higher turbine inlet temperatures lead to higher electrical efficiencies at all values of $\Pi$. As a result, the net electrical efficiency is maximized at $15.2 \%$, $17.0 \%, 18.8 \%$ and $20.4 \%$ for turbine inlet temperatures of $750{ }^{\circ} \mathrm{C}, 800{ }^{\circ} \mathrm{C}, 850{ }^{\circ} \mathrm{C}$ and $900{ }^{\circ} \mathrm{C}$, respectively. The optimum operating conditions were found for pressure ratios from 3.8 to 5.0. However, when turbine inlet temperatures approach $900{ }^{\circ} \mathrm{C}$, expensive and complex cooling systems are required, thereby increasing the capital expenditure and maintenance costs of the power generation unit $[14,17]$. Therefore, under a conservative perspective, the turbine inlet temperature was finally adjusted to $850{ }^{\circ} \mathrm{C}$ by setting the fuel-air equivalence ratio $(\varphi)$ at 0.12 , achieving a net electric power generation of about $275 \mathrm{~kW}_{\mathrm{e}}$, with an optimum electrical efficiency of $18.8 \%$ at a pressure ratio equal to 4.7 .

The net electrical efficiency of the gasifier-microturbine system is comparable to that of previous works $[14,17,18$, $20,22]$. Even though a rather lower electrical efficiency is attained with respect to that of a conventional microturbine fueled with high-quality fossil fuels such as natural gas, the gasifier-microturbine system of the present work is ultimately fueled with an inexpensive solid feedstock of renewable nature that is massively produced on site. It is noteworthy that olive oil mills are currently spending a substantial part of their incomes in order to dispose of the wet olive pomace. The net electric power of the integrated gasification plant considering the electricity consumption by the pelletizer and all the ancillary equipment is estimated at around $220-250 \mathrm{~kW}_{\mathrm{e}}$ or roughly $10-20 \%$ of the net electric power generation from the microturbine. Lastly, the volume flow rate of hot exhaust gases discharged from the microturbine is about $15,800 \mathrm{~m}^{3} / \mathrm{h}$ at $300{ }^{\circ} \mathrm{C}$, constituting a yet available thermal power of roughly $800 \mathrm{~kW}_{\text {th }}$.

\subsection{Rotary drum dryer}

The feedstock to be dried in the co-current flow rotary drum is wet olive pomace, the moisture content (wet basis) of which is quite variable throughout the year, usually ranging between 60 and $70 \%$, although sometimes reaching higher values up to about $80 \%$ moisture content.
Fig. 7 Effect of the moisture content of wet olive pomace at the dryer inlet on the yield of dry pomace

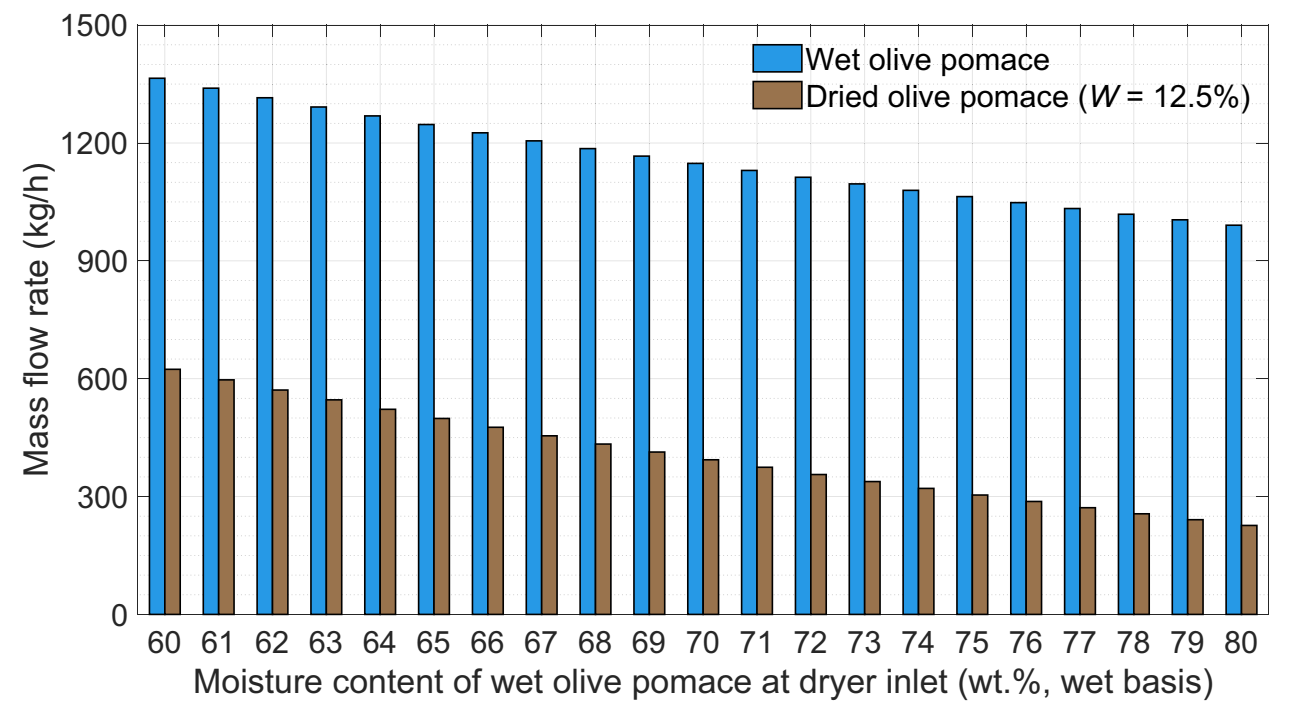


Figure 7 shows the results of a performance analysis with different moisture contents of the feedstock ranging from 60 to $80 \%$. The wet olive pomace from oil mills is dried with the hot gases from the microturbine exhaust down to a $12.5 \%$ moisture content in order to be supplied into the downdraft gasifier in a self-sufficient process. As illustrated, the higher the moisture content of the feedstock to the rotary drum dryer, the lower the mass flow rates of wet feedstock and dried product. It is noteworthy that if the initial moisture content of wet pomace is greater than $75 \%$, the mass flow rate of dried pomace becomes insufficient to feed the downdraft gasifier in a self-sustaining process. Considering from here on an average moisture content of $65 \%$ [4], the mass flow rate of wet olive pomace into the rotary drum dryer was approximately $1250 \mathrm{~kg} / \mathrm{h}$, yielding about $500 \mathrm{~kg} / \mathrm{h}$ of dried product. This represents a surplus of around $200 \mathrm{~kg} / \mathrm{h}$ over the mass flow rate of dried pomace consumed by the downdraft gasifier.

The main performance parameters of the co-current flow rotary drum dryer are outlined in Table 3 . The diameter of the dryer drum or shell was estimated at approximately $2 \mathrm{~m}$ by considering the volume flow rate of hot exhaust gas at the dryer inlet. As rotary drum dryers typically have a length to diameter $(L / D)$ ratio ranging between 4 and 10 , the selected $L / D$ ratio was 7 , the average value $[57,60]$. Consequently, a 14-m long rotary drum dryer was modeled in this work [66]. In practice, the optimal sizing of the dryer should consider its cost, together with the temperature and moisture content of the outlet streams. However, different geometries for the dryer are acceptable as long as the temperature and outlet moisture content of the feedstock and drying gas are in a reasonable range [66]. The residence time of the wet olive pomace was set as the average value in a typical rotary drum dryer of $20 \mathrm{~min}[59,61,63]$. The drying thermal efficiency $\left(\eta_{t h}\right)$, determined according to Eq. (22), was 58.8\%, which lies very close to the value reported in [66], and within the typical 35-70\% range of drying thermal efficiencies for rotary drum dryers [57]. The rest of the available thermal energy in the hot exhaust gases was lost through the dryer body and vent to the atmosphere. The energy efficiency

Table 3 Dryer simulation specifications and performance parameters

\begin{tabular}{lll}
\hline Parameter & Value & Unit \\
\hline Dimensions (diameter $\times$ length) & $2 \times 14$ & $\mathrm{~m} \times \mathrm{m}$ \\
Mass flow rate of wet feedstock $(W=65 \%)$ & 1250 & $\mathrm{~kg} / \mathrm{h}$ \\
Mass flow rate of dried product $(W=12.5 \%)$ & 500 & $\mathrm{~kg} / \mathrm{h}$ \\
Thermal energy supply & 800 & $\mathrm{~kW}$ \\
Residence time & 20 & $\mathrm{~min}$ \\
Drying thermal efficiency $\left(\eta_{t h}\right)$ & 58.8 & $\%$ \\
Drying efficiency $\left(\eta_{d r y}\right)$ & 32.2 & $\%$ \\
\hline
\end{tabular}

of the drying stage $\left(\eta_{d r y}\right)$, calculated as shown in Eq. (23), was $32.2 \%$. This value adds up to the previously determined electrical efficiency of the integrated gasification plant $\left(\eta_{e}=18.8 \%\right)$, resulting in a satisfactory overall efficiency $\left(\eta_{o}\right)$ of $51.0 \%$.

Finally, the temperature and moisture content profiles of the drying exhaust gas and the wet olive pomace along the dryer length are displayed in Fig. 8. The temperature of the exhaust gas decreases drastically as its humidity increases, leading to a substantial reduction in the moisture content of olive pomace along the dryer. According to Eq. (12), the mass flow rate of moisture evaporating from the wet olive pomace must correspond to the increase in humidity of the drying gas. The initial moisture content of the wet olive pomace to be dried in the co-current rotary drum dryer was $65 \%$ on a wet basis $(1.857 \mathrm{~kg}$ water $/ \mathrm{kg}$ dry solid), while the drying exhaust gas was continuously discharged from the microturbine with an absolute humidity of $0.019 \mathrm{~kg}$ water/ $\mathrm{kg}$ dry gas. The moisture content of the solid feedstock was reduced down to $12.5 \%$ on a wet basis $(0.143 \mathrm{~kg}$ water $\mathrm{kg} /$ dry solid) and the absolute humidity of the drying exhaust gas at the dryer outlet was $0.096 \mathrm{~kg}$ water $/ \mathrm{kg}$ dry gas, corresponding to a relative humidity of about $12.3 \%$. The dryer thermal requirement was approximately $3.8 \mathrm{MJ} / \mathrm{kg}$ of evaporated water, which lies within the reported range for industrial rotary drum dryers [71].

\subsection{Overall energy balance}

In order to provide an overview of the energy flows and losses, a power loss evaluation of the integrated gasification plant was performed. Figure 9 conveniently displays the overall energy balance of the integrated gasification plant in a Sankey diagram. As can be observed, $51.0 \%$ of the input chemical energy in the feedstock to the downdraft gasifier is converted into electric power $\left(\eta_{e}=18.8 \%\right)$ and useful heat for moisture evaporation $\left(\eta_{d r y}=32.2 \%\right)$. The remaining $49.0 \%$ of the energy flow represents thermal losses in the form of heat release toward the environment through various units of the integrated gasification plant. The major sources of power losses are the producer gas cooling and cleaning unit $(18.4 \%)$ and the rotary drum dryer $(22.7 \%)$. Heating of unconverted carbon and ashes in the charcoal discharged from the gasifier constitutes the next source of energy losses in terms of importance (5.1\%). Power conversion losses in the electric generator of the microturbine only represent $2.7 \%$ of the input energy flow. Electricity consumption by the pelletizer and rest of ancillary equipment is estimated at approximately $14.5 \%$ of the net electric power generation from the microturbine. As a result, the net electric power for self-consumption by the olive oil mill is estimated at $16.1 \%$ of the input energy flow. 
Fig. 8 Temperature and moisture content profiles of the wet olive pomace and the drying exhaust gas along the co-current rotary drum dryer
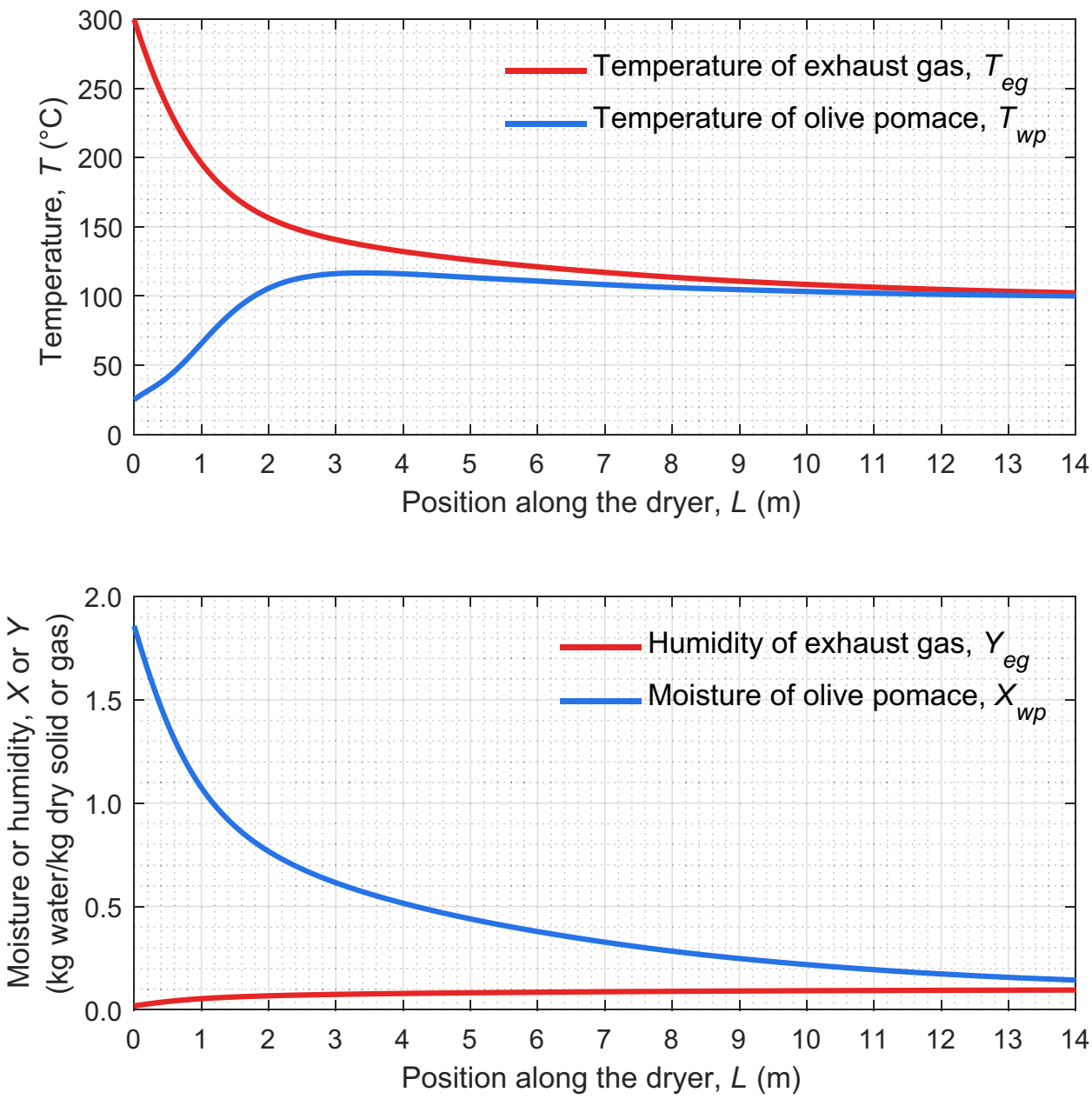

Fig. 9 Sankey diagram of the integrated gasification plant

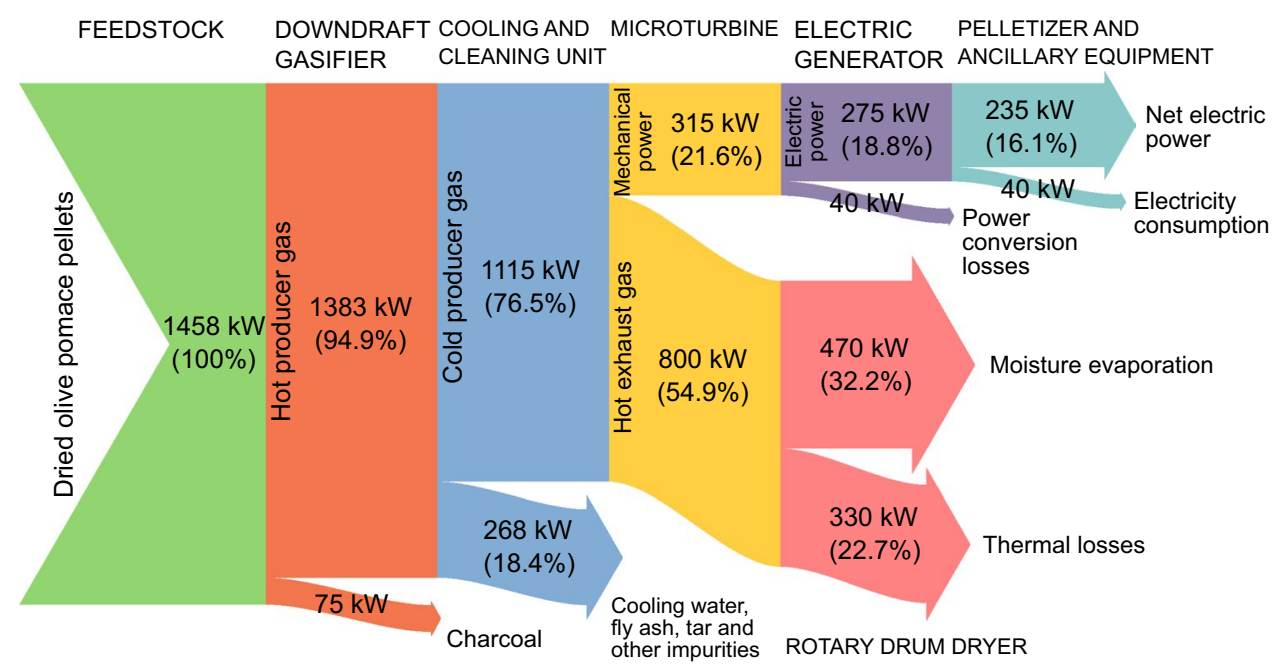

\section{Economic feasibility assessment}

This last section aims at demonstrating the economic feasibility of an integrated gasification plant with a net electric power of about $220-250 \mathrm{~kW}_{\mathrm{e}}$ for the olive oil industry. The following assumptions were considered for the economic feasibility assessment:

- The integrated gasification plant operates continuously during approximately 4 and a half months, spanning 
the whole olive oil production period. The gasification plant only requires two monthly maintenance stops.

- The cost of a gasification plant of similar size $(370,000$ $€)$ was directly consulted with manufacturers. The cost of the microturbine is estimated at roughly $1000 € / \mathrm{kW}_{\mathrm{e}}$ [72], while the cost of the co-current flow rotary drum dryer $(200,000 €)$ and pelletizer $(50,000 €)$ were consulted with a local manufacturer. The fixed and installation costs of the gasification plant (civil works, electrical and mechanical assemblies) are estimated as $20 \%$ of the total investment. As a result, the turnkey cost of the integrated gasification plant is estimated at 1,074,000 €.

- Non-refundable subsidies from public funding organizations are currently available for sustainable small and medium size companies. These subsidies, which can fund up to a $40 \%$ of the total investment, may be provided by the Center for the Development of Industrial Technology (CDTI) at national level in Spain or by the Andalusian Energy Agency at regional level in the Autonomous Community of Andalusia. A 35\% non-refundable subsidy was considered in this work [73].
- The gasification plant is intended for self-consumption of renewable electricity, as established in the Spanish law (Royal Decree 244/2019) [74], leading to a substantial reduction in the variable term of the cost of electricity for most olive oil mills.

- Another by-product affecting the profitability potential of the gasification technology in the olive oil industry is the charcoal discharged from the downdraft gasifier, also known commercially as biochar. The average sale price of this by-product from gasification in international markets is estimated at around $0.15 € / \mathrm{kg}[75,76]$; whereas in England, for instance, a higher sale price ranging between 0.16 and $0.48 € / \mathrm{kg}$ has been reported [77]. One of the reasons for the high variability in the sale price of this by-product is the wide variation in its physicochemical characteristics, as well as its diversity of potential uses and associated markets [76]. To this end, biochar certification standards by organizations such as the International Biochar Initiative (IBI) and the European Biochar Certificate (EBC) are available [78]. Among the criteria considered by these standards are the carbon content, molar $\mathrm{H} / \mathrm{C}$ ratio, surface area and concentration of contaminants such as
Table 4 Input parameters and results of the economic feasibility assessment of the integrated gasification plant

\begin{tabular}{|c|c|c|}
\hline & Value & Unit \\
\hline \multicolumn{3}{|l|}{ Plant performance parameters } \\
\hline Gross electric power & 275 & $\mathrm{~kW}_{\mathrm{e}}$ \\
\hline Net electric power & $220-250$ & $\mathrm{~kW}_{\mathrm{e}}$ \\
\hline Available thermal power & 800 & $\mathrm{~kW}_{\mathrm{th}}$ \\
\hline Consumption of wet feedstock $(W=65 \%)$ & 300 & $\mathrm{~kg} / \mathrm{h}$ \\
\hline Working hours & 3,100 & $\mathrm{~h} /$ year \\
\hline Plant operational lifespan & 15 & years \\
\hline Biochar production & 6.5 & $\%$ on input biomass \\
\hline \multicolumn{3}{|l|}{ Economic parameters } \\
\hline Annual rate of discount & 1.5 & $\%$ \\
\hline Estimated turnkey cost of the gasification plant & $1,074,000$ & $€$ \\
\hline - Gasifier + cooling and cleaning unit & 370,000 & $€$ \\
\hline - Microturbine & 275,000 & $€$ \\
\hline - Rotary drum dryer & 200,000 & $€$ \\
\hline - Pelletizer & 50,000 & $€$ \\
\hline - Installation, assembly and commissioning & 179,000 & $€$ \\
\hline Non-refundable subsidies & 35 & $\%$ of total investment \\
\hline Total oil mill capital investment & 698,100 & $€$ \\
\hline Operation and maintenance cost & 0.01 & $€ / \mathrm{kWh}$ \\
\hline Labor hiring cost & 20,000 & $€ /$ year \\
\hline Electricity self-consumption, sale price & 0.10 & $€ / \mathrm{kWh}$ \\
\hline Biochar, sale price & 0.15 & $€ / \mathrm{kg}$ \\
\hline Transportation costs of wet olive pomace, savings & 6 & $€ / \mathrm{t}$ \\
\hline \multicolumn{3}{|l|}{ Results } \\
\hline Payback period & $7-9$ & years \\
\hline Payback period (without hiring cost) & $6-8$ & years \\
\hline
\end{tabular}


heavy metals, polycyclic aromatic hydrocarbons (PAHs), polychlorinated biphenyls (PCB), dioxins and furans.

- The savings in the transportation costs of wet olive pomace are estimated at $6 € / t$, considering an average distance between the olive oil mill and the olive pomace oil extraction plant of about $50 \mathrm{~km}$.

- The integrated gasification plant may involve hiring a part-time employee for permanent operation and maintenance works. In such case, a hiring cost of 20,000 €/year was considered.

- Finally, the annual rate of discount was assumed equal to $1.5 \%$.

The input data and results of the economic feasibility assessment are reported in Table 4.

Table 4 reveals that, if a new part-time operation and maintenance job is created, the investment shows a reasonable payback period ranging between 7 and 9 years. However, if the already available operation and maintenance staff in most olive oil mills receive sufficient training on the gasification technology, the return on investment could be reduced down to about 6-8 years. Under both circumstances, the investment would provide a net present benefit (NPV) above 500,000 € during the plant operational lifespan.

\section{Conclusions}

This research work proposes an integrated gasification plant as an alternative approach for the current management of wet olive pomace, a waste stream that is produced at massive rates and represents an increasing expense for Spanish oil mills, because it must be continuously transported to olive pomace oil extraction plants in order to avoid production stoppages. The integrated plant consists of a pelletizer, a downdraft gasifier fueled with dried olive pomace pellets, a producer gas cooling and cleaning unit, a microturbine and a co-current flow rotary drum dryer. Apart from the electric power generation for self-consumption in the microturbine, the hot exhaust gases discharged at temperatures close to $300{ }^{\circ} \mathrm{C}$ can be used for drying wet olive pomace in the rotary drum dryer, allowing a self-sufficient operation of the integrated gasification plant. A comprehensive process simulation model was developed in Aspen Plus to conduct the mass and energy balances of the proposed plant. The model was validated against experimental and simulation results of relevant works. The simulation results show an electrical efficiency of $18.8 \%$ under optimum operating conditions, while the drying stage allows achieving a satisfactory overall efficiency of $51.0 \%$. The plant performance parameters are reasonably good, considering that an inexpensive wet by-product of olive oil production that is mass-produced onsite is used as feedstock for renewable electricity generation. Accordingly, the integrated gasification plant is regarded as an interesting and potentially feasible option for most oil mills to invest in electric self-sufficiency through waste management and recovery. The developed model could be used to conduct more detailed process economics and safety assessments of a prospective commercial scale plant.

\section{Nomenclature}

$c_{p}$ : Mass heat capacity $\left(\mathrm{kJ}^{\mathrm{kg}} \mathrm{kg}^{-1} \cdot \mathrm{K}^{-1}\right) ; d_{m}$ : Median particle diameter $(\mathrm{m}) ; d_{32}$ : Sauter mean diameter $(\mathrm{m}) ; h$ : Specific enthalpy $\left(\mathrm{kJ}^{\mathrm{kg}} \mathrm{kg}^{-1} \cdot \mathrm{K}^{-1}\right) ; \Delta H_{\text {vap }}$ : Enthalpy of vaporization of water $\left(\mathbf{k J} \cdot \mathrm{kg}^{-1}\right) ; \dot{m}$ : Mass flow rate $\left(\mathbf{k g} \cdot \mathrm{h}^{-1}\right) ; \dot{n}$ : Mole flow rate $\left(\mathrm{kmole} \cdot \mathrm{h}^{-1}\right) ; \mathrm{k}$ : Thermal conductivity $\left(\mathrm{kW} \cdot \mathrm{m}^{-1} \cdot \mathrm{K}^{-1}\right)$; LHV: Lower heating value ( $\mathrm{MJ} \cdot \mathrm{kg}^{-1}$ or $\left.\mathrm{MJ} \cdot \mathrm{Nm}^{-3}\right)$; $p$ : Pressure (kPa); $P$ : Power (kW); T: Temperature (K); TIT: Turbine inlet temperature $\left({ }^{\circ} \mathrm{C}\right)$; $u$ :Velocity $\left(\mathrm{m} \cdot \mathrm{s}^{-1}\right)$; W: Moisture, wet basis (kg water/kg mixture); $X:$ Moisture, dry basis (kg water/kg dry solid); $y:$ Mole fraction; $Y:$ Humidity (kg water/kg dry gas)

\section{Dimensionless numbers}

Le: Lewis number; Re: Reynolds number; Sc: Schmidt number; Sh: Sherwood number

\section{Greek letters}

$a$ : Heat transfer coefficient $\left(\mathrm{kW} \cdot \mathrm{m}^{-2} \cdot \mathrm{K}^{-1}\right) ; \beta$ : Mass transfer coefficient $\left(m \cdot s^{-1}\right) ; \delta$ : Gas diffusivity $\left(m^{2} \cdot s^{-1}\right) ; \varphi$ : Fuel-air equivalence ratio; $\eta$ : Efficiency; $\lambda$ : Air-fuel equivalence ratio; $\mu$ : Dynamic viscosity $\left(\mathbf{k g} \cdot \mathrm{m}^{-1} \cdot \mathrm{s}^{-1}\right) ; \Pi$ : Pressure ratio; $\rho:$ Mass density $\left(\mathbf{k g} \cdot \mathrm{m}^{-3}\right)$

\section{Subscripts}

air: Air; cc: Carbon conversion; cg: Cold gas; comp: Compressor; $d p$ : Dried olive pomace; $d r y$ : Drying; e: Electrical; eg: Exhaust gas; gen: Generator; hg: Hot gas; i: Isentropic; $m$ : Mechanical; o: Overall; s: Solid; th: Thermal; turb: Turbine; $w$ : Water; $w p$ : Wet olive pomace

Funding Open Access funding provided thanks to the CRUE-CSIC agreement with Springer Nature. This research work was supported by the project entitled "Opportunities for olive oil value chain enhancement through the by-products valorization (OLIVEN)", funded through the ARIMNet2 2017 Joint Call by Agencia Estatal de Investigación (Ref. PCI2018-093255). ARIMNet2 (ERANET) has received funding from the European Union within the Seventh Framework Program for research, technological development and demonstration activities under grant agreement no. 618127.

Roque Aguado gratefully acknowledges financial support from the Ministerio de Universidades under the FPU Program (Ref. FPU19/00930).

Open Access This article is licensed under a Creative Commons Attribution 4.0 International License, which permits use, sharing, adaptation, distribution and reproduction in any medium or format, as long as you give appropriate credit to the original author(s) and the source, provide a link to the Creative Commons licence, and indicate if changes were made. The images or other third party material in this article are 
included in the article's Creative Commons licence, unless indicated otherwise in a credit line to the material. If material is not included in the article's Creative Commons licence and your intended use is not permitted by statutory regulation or exceeds the permitted use, you will need to obtain permission directly from the copyright holder. To view a copy of this licence, visit http://creativecommons.org/licenses/by/4.0/.

\section{References}

1. FAOSTAT. http://www.fao.org/faostat/en/\#home. Accessed 18 Apr 2021

2. Economic affairs \& promotion unit - International Olive Council. https://www.internationaloliveoil.org/what-we-do/economic-affai rs-promotion-unit/\#figures. Accessed 18 Apr 2021

3. Patsios SI, Kontogiannopoulos KN, Banias GF (2021) Environmental impact assessment in agri-production. Bio-Economy and Agri-production. Elsevier, Amsterdam, pp 83-116

4. Arjona R, García A, Ollero P (1999) Drying of alpeorujo, a waste product of the olive oil mill industry. J Food Eng 41:229-234. https://doi.org/10.1016/S0260-8774(99)00104-1

5. Serrano A, Villa-Gomez D, Fermoso FG, Alonso-Fariñas B (2021) Is anaerobic digestion a feasible alternative to the combustion of olive mill solid waste in terms of energy production? A critical review. Biofuels, Bioprod Biorefining 15:150-162. https:// doi.org/10.1002/bbb.2159

6. Sánchez-Sánchez C, González-González A, Cuadros-Salcedo F, Cuadros-Blázquez F (2020) Two-phase Olive mill waste: a circular economy solution to an imminent problem in Southern Europe. J Clean Prod 274:122789. https://doi.org/10.1016/j.jclepro.2020. 122789

7. García-Maraver A, Zamorano M, Ramos-Ridao A, Díaz LF (2012) Analysis of olive grove residual biomass potential for electric and thermal energy generation in Andalusia (Spain). Renew Sustain Energy Rev 16:745-751. https://doi.org/10.1016/j.rser.2011.08. 040

8. Vera D, Jurado F, De Mena B, Hernández JC (2019) A distributed generation hybrid system for electric energy boosting fueled with olive industry wastes. Energies 12:030500. https://doi.org/ 10.3390/en12030500

9. Gómez-de la Cruz FJ, Palomar-Carnicero JM, Hernández-Escobedo Q, Cruz-Peragón F (2020) Determination of the drying rate and effective diffusivity coefficients during convective drying of two-phase olive mill waste at rotary dryers drying conditions for their application. Renew Energy 153:900-910. https://doi.org/10. 1016/j.renene.2020.02.062

10. Alonso-Fariñas B, Oliva A, Rodríguez-Galán M et al (2020) Environmental assessment of olive mill solid waste valorization via anaerobic digestion versus olive pomace oil extraction. Process 8:626

11. Basu P (2018) Biomass gasification, pyrolysis and torrefaction: practical design and theory. Elsevier, Amsterdam

12. Ruiz JA, Juárez MC, Morales MP et al (2013) Biomass gasification for electricity generation: review of current technology barriers. Renew Sustain Energy Rev 18:174-183. https://doi.org/10. 1016/j.rser.2012.10.021

13. Loeser M, Redfern MA (2010) Modelling and simulation of a novel micro-scale combined feedstock biomass generation plant for grid-independent power supply. Int J Energy Res 34:303-320. https://doi.org/10.1002/er.1556

14. Vera D, Jurado F, Panopoulos KD, Grammelis P (2012) Modelling of biomass gasifier and microturbine for the olive oil industry. Int J Energy Res 36:355-367. https://doi.org/10.1002/er.1802
15. Zornek T, Monz T, Aigner M (2015) Performance analysis of the micro gas turbine Turbec T100 with a new FLOX-combustion system for low calorific fuels. Appl Energy 159:276-284. https:// doi.org/10.1016/j.apenergy.2015.08.075

16. Rabou LPLM, Grift JM, Conradie RE, Fransen S (2008) Micro gas turbine operation with biomass producer gas and mixtures of biomass producer gas and natural gas. Energy Fuels 22:19441948. https://doi.org/10.1021/ef700630z

17. Vera D, Jurado F, de Mena B, Schories G (2011) Comparison between externally fired gas turbine and gasifier-gas turbine system for the olive oil industry. Energy 36:6720-6730. https://doi. org/10.1016/j.energy.2011.10.036

18. Henao NC, Lora EES, Maya DMY et al (2019) Technical feasibility study of $200 \mathrm{~kW}$ gas microturbine coupled to a dual fluidized bed gasifier. Biomass Bioenerg 130:105369. https://doi.org/10. 1016/j.biombioe.2019.105369

19. Lan W, Chen G, Zhu X et al (2018) Biomass gasification-gas turbine combustion for power generation system model based on ASPEN PLUS. Sci Total Environ 628-629:1278-1286. https:// doi.org/10.1016/j.scitotenv.2018.02.159

20. Abd El-Sattar H, Kamel S, Tawfik MA et al (2019) Modeling and simulation of corn stover gasifier and micro-turbine for power generation. Waste Biomass Valoriz 10:3101-3114. https://doi.org/ 10.1007/s12649-018-0284-z

21. Jia J, Abudula A, Wei L et al (2015) Effect of operating parameters on performance of an integrated biomass gasifier, solid oxide fuel cells and micro gas turbine system. Biomass Bioenerg 75:35-45. https://doi.org/10.1016/j.biombioe.2015.02.004

22. Perna A, Minutillo M, Jannelli E et al (2018) Performance assessment of a hybrid SOFC/MGT cogeneration power plant fed by syngas from a biomass down-draft gasifier. Appl Energy 227:8091. https://doi.org/10.1016/j.apenergy.2017.08.077

23. Minutillo M, Perna A, Jannelli E et al (2017) Coupling of biomass gasification and SOFC - gas turbine hybrid system for small scale cogeneration applications. Energy Procedia 105:730-737. https:// doi.org/10.1016/j.egypro.2017.03.383

24. Salisu J, Gao N, Quan C (2021) Techno-economic assessment of co-gasification of rice husk and plastic waste as an off-grid power source for small scale rice milling - an Aspen Plus model. J Anal Appl Pyrolysis 158:105157. https://doi.org/10.1016/j.jaap.2021. 105157

25. Pilavachi PA (2002) Mini- and micro-gas turbines for combined heat and power. Appl Therm Eng 22:2003-2014. https://doi.org/ 10.1016/S1359-4311(02)00132-1

26. Al Moussawi H, Fardoun F, Louahlia-Gualous H (2016) Review of tri-generation technologies: design evaluation, optimization, decision-making, and selection approach. Energy Convers Manag 120:157-196. https://doi.org/10.1016/j.enconman.2016.04.085

27. Wegener M, Malmquist A, Isalgué A, Martin A (2018) Biomassfired combined cooling, heating and power for small scale applications - a review. Renew Sustain Energy Rev 96:392-410. https:// doi.org/10.1016/j.rser.2018.07.044

28. Kaparaju P, Rintala J (2013) Generation of heat and power from biogas for stationary applications: boilers, gas engines and turbines, combined heat and power (CHP) plants and fuel cells. Biogas Handb Sci Prod Appl. https://doi.org/10.1533/9780857097 415.3.404

29. Wojnicka B, Ściążko M, Schmid JC (2019) Modelling of biomass gasification with steam. Biomass Convers Biorefinery 11:17871805. https://doi.org/10.1007/S13399-019-00575-2

30. Patel VR, Upadhyay DS, Patel RN (2014) Gasification of lignite in a fixed bed reactor: influence of particle size on performance of downdraft gasifier. Energy 78:323-332. https://doi.org/10.1016/j. energy.2014.10.017 
31. AspenTech (2013) Getting started modeling processes with solids V8.4. Aspen Technology Inc., Bedford

32. Tavares R, Monteiro E, Tabet F, Rouboa A (2020) Numerical investigation of optimum operating conditions for syngas and hydrogen production from biomass gasification using Aspen Plus. Renew Energy 146:1309-1314. https://doi.org/10.1016/j.renene. 2019.07.051

33. Safarian S, Unnthorsson R, Richter C (2020) Performance analysis and environmental assessment of small-scale waste biomass gasification integrated CHP in Iceland. Energy 197:117268. https:// doi.org/10.1016/j.energy.2020.117268

34. Pilar González-Vázquez M, Rubiera F, Pevida C et al (2021) Thermodynamic analysis of biomass gasification using Aspen Plus: comparison of stoichiometric and non-stoichiometric models. Energies 14:189. https://doi.org/10.3390/en14010189

35. Cirillo D, Di Palma M, La Villetta M et al (2021) A novel biomass gasification micro-cogeneration plant: experimental and numerical analysis. Energy Convers Manag 243:114349. https://doi.org/ 10.1016/j.enconman.2021.114349

36. AspenTech (2001) Aspen Physical Property System 11.1. Aspen Technology, Inc., Bedford

37. Han J, Liang Y, Hu J et al (2017) Modeling downdraft biomass gasification process by restricting chemical reaction equilibrium with Aspen Plus. Energy Convers Manag 153:641-648. https:// doi.org/10.1016/j.enconman.2017.10.030

38. Kuo PC, Wu W, Chen WH (2014) Gasification performances of raw and torrefied biomass in a downdraft fixed bed gasifier using thermodynamic analysis. Fuel 117:1231-1241. https://doi.org/10. 1016/j.fuel.2013.07.125

39. Gagliano A, Nocera F, Bruno M, Cardillo G (2017) Development of an equilibrium-based model of gasification of biomass by Aspen Plus. Energy Procedia 111:1010-1019. https://doi.org/ 10.1016/j.egypro.2017.03.264

40. Baruah D, Baruah DC (2014) Modeling of biomass gasification: a review. Renew Sustain Energy Rev 39:806-815. https://doi.org/ 10.1016/j.rser.2014.07.129

41. de Mena B, Vera D, Jurado F, Ortega M (2017) Updraft gasifier and ORC system for high ash content biomass: a modelling and simulation study. Fuel Process Technol 156:394-406. https://doi. org/10.1016/j.fuproc.2016.09.031

42. Altafini CR, Wander PR, Barreto RM (2003) Prediction of the working parameters of a wood waste gasifier through an equilibrium model. Energy Convers Manag 44:2763-2777. https://doi. org/10.1016/S0196-8904(03)00025-6

43. Abuadala A, Dincer I, Naterer GF (2010) Exergy analysis of hydrogen production from biomass gasification. Int J Hydrogen Energy 35:4981-4990. https://doi.org/10.1016/j.ijhydene.2009. 08.025

44. Mutlu ÖÇ, Zeng T (2020) Challenges and opportunities of modeling biomass gasification in Aspen Plus: a review. Chem Eng Technol 43:1674-1689. https://doi.org/10.1002/ceat.202000068

45. Zhao S, Bi X, Pan X et al (2019) (2019) The optimization of insitu tar reduction and syngas production on a $60-\mathrm{kW}$ three-staged biomass gasification system: theoretical and practical approach. Biomass Convers Biorefinery 115(11):1835-1846. https://doi.org/ 10.1007/S13399-019-00536-9

46. Safarian S, Unnpórsson R, Richter C (2019) A review of biomass gasification modelling. Renew Sustain Energy Rev 110:378-391. https://doi.org/10.1016/j.rser.2019.05.003

47. Karamarkovic R, Karamarkovic V (2010) Energy and exergy analysis of biomass gasification at different temperatures. Energy 35:537-549. https://doi.org/10.1016/j.energy.2009.10.022

48. Jarungthammachote S, Dutta A (2008) Equilibrium modeling of gasification: Gibbs free energy minimization approach and its application to spouted bed and spout-fluid bed gasifiers. Energy
Convers Manag 49:1345-1356. https://doi.org/10.1016/j.encon man.2008.01.006

49. Bassyouni M, Ul Hasan SW, Abdel-Aziz MH et al (2014) Date palm waste gasification in downdraft gasifier and simulation using ASPEN HYSYS. Energy Convers Manag 88:693-699. https://doi. org/10.1016/j.enconman.2014.08.061

50. Broer KM, Brown RC (2015) The role of char and tar in determining the gas-phase partitioning of nitrogen during biomass gasification. Appl Energy 158:474-483. https://doi.org/10. 1016/j.apenergy.2015.08.100

51. Jangsawang W, Laohalidanond K, Kerdsuwan S (2015) Optimum equivalence ratio of biomass gasification process based on thermodynamic equilibrium model. Energy Procedia 79:520 527. https://doi.org/10.1016/j.egypro.2015.11.528

52. Martínez JD, Mahkamov K, Andrade RV, Silva Lora EE (2012) Syngas production in downdraft biomass gasifiers and its application using internal combustion engines. Renew Energy 38:19. https://doi.org/10.1016/j.renene.2011.07.035

53. Zainal ZA, Rifau A, Quadir GA, Seetharamu KN (2002) Experimental investigation of a downdraft biomass gasifier. Biomass Bioenerg 23:283-289. https://doi.org/10.1016/S0961-9534(02) 00059-4

54. Zhang R, Basu P (2004) A simple model for prediction of solid collection efficiency of a gas-solid separator. Powder Technol 147:86-93. https://doi.org/10.1016/j.powtec.2004.09.009

55. Laranci P, Bursi E, Fantozzi F (2011) Numerical analysis of a microturbine combustion chamber modified for biomass derived syngas. In: Proceedings of the ASME Turbo Expo. American Society of Mechanical Engineers Digital Collection, pp 541-548

56. Visser WPJ, Shakariyants SA, Oostveen M (2011) Development of a $3 \mathrm{~kW}$ microturbine for CHP applications. J Eng Gas Turbines Power 133:042301. https://doi.org/10.1115/1.4002156

57. Mujumdar AS (2014) Handbook of industrial drying, 4th edn. CRC Press

58. Bustamante CA, Hill AF, Rodríguez DF et al (2014) Modeling and simulation of a co-current rotary dryer under steady conditions. Dry Technol 32:469-475. https://doi.org/10.1080/07373937.2013. 838584

59. Han J, Kim J (2018) Process simulation and optimization of 10-MW EFB power plant. Comput Aided Chem Eng 43:723-729. https://doi.org/10.1016/B978-0-444-64235-6.50128-5

60. Han J, Choi Y, Kim J (2020) Development of the process model and optimal drying conditions of biomass power plants. ACS Omega. https://doi.org/10.1021/acsomega.9b03557

61. Gómez-de la Cruz FJ, Casanova-Peláez PJ, Palomar-Carnicero JM, Cruz-Peragón F (2015) Modeling of olive-oil mill waste rotary dryers: green energy recovery systems. Appl Therm Eng 80:362-373. https://doi.org/10.1016/j.applthermaleng.2015.01. 035

62. Castaño F, Rubio FR, Ortega MG (2012) Modeling of a cocurrent rotary dryer. Dry Technol 30:839-849. https://doi.org/10.1080/ 07373937.2012.668998

63. Gómez-de la Cruz FJ, Casanova-Peláez PJ, Palomar-Carnicero JM, Cruz-Peragón F (2017) Characterization and analysis of the drying real process in an industrial olive-oil mill waste rotary dryer: a case of study in Andalusia. Appl Therm Eng 116:1-10. https://doi.org/10.1016/j.applthermaleng.2017.01.050

64. van Meel DA (1958) Adiabatic convection batch drying with recirculation of air. Chem Eng Sci 9:36-44. https://doi.org/10.1016/ 0009-2509(58)87005-0

65. Kemp IC (2007) Drying software: past, present, and future. Dry Technol 25:1249-1263. https://doi.org/10.1080/0737393070 1438709

66. Manouchehrinejad M, Mani S (2019) Process simulation of an integrated biomass torrefaction and pelletization (iBTP) plant 
to produce solid biofuels. Energy Convers Manag X 1:100008. https://doi.org/10.1016/j.ecmx.2019.100008

67. García R, Gil MV, Rubiera F, Pevida C (2019) Pelletization of wood and alternative residual biomass blends for producing industrial quality pellets. Fuel 251:739-753. https://doi.org/10.1016/j. fuel.2019.03.141

68. Puig-Arnavat M, Bruno JC, Coronas A (2010) Review and analysis of biomass gasification models. Renew Sustain Energy Rev 14:2841-2851. https://doi.org/10.1016/j.rser.2010.07.030

69. Vera D, Jurado F, Carpio J, Kamel S (2018) Biomass gasification coupled to an EFGT-ORC combined system to maximize the electrical energy generation: a case applied to the olive oil industry. Energy 144:41-53. https://doi.org/10.1016/j.energy.2017.11.152

70. Jayah TH, Aye L, Fuller RJ, Stewart DF (2003) Computer simulation of a downdraft wood gasifier for tea drying. Biomass Bioenerg 25:459-469. https://doi.org/10.1016/S0961-9534(03)00037-0

71. Li H, Chen Q, Zhang X et al (2012) Evaluation of a biomass drying process using waste heat from process industries: a case study. Appl Therm Eng 35:71-80. https://doi.org/10.1016/j.appltherma leng.2011.10.009

72. Galanti L, Massardo AF (2010) Thermoeconomic analysis of micro gas turbine design in the range $25-500 \mathrm{kWe}$. Proc ASME Turbo Expo 5:317-327. https://doi.org/10.1115/GT2010-22351

73. Orden de 23 de diciembre de 2016, por la que se aprueban las bases reguladoras para la concesión de incentivos para el desarrollo energético sostenible de Andalucía en el período 2017-2020. https://www.juntadeandalucia.es/boja/2016/249/3.html. Accessed 18 Apr 2021

74. BOE.es - BOE-A-2019-5089 Real Decreto 244/2019, de 5 de abril, por el que se regulan las condiciones administrativas, técnicas y económicas del autoconsumo de energía eléctrica. https:// www.boe.es/buscar/doc.php?id=BOE-A-2019-5089. Accessed 18 Apr 2021

75. Hagemann N, Joseph S, Schmidt HP et al (2017) Organic coating on biochar explains its nutrient retention and stimulation of soil fertility. Nat Commun 8:1-11. https://doi.org/10.1038/ s41467-017-01123-0

76. Campbell RM, Anderson NM, Daugaard DE, Naughton HT (2018) Financial viability of biofuel and biochar production from forest biomass in the face of market price volatility and uncertainty. Appl Energy 230:330-343. https://doi.org/10.1016/j.apene rgy.2018.08.085

77. Vacheron J, Desbrosses G, Bouffaud ML et al (2013) Plant growth-promoting rhizobacteria and root system functioning. Front Plant Sci 4:356. https://doi.org/10.3389/fpls.2013.00356

78. European Biochar Foundation (2013) Comparison of European biochar certificate version 4.8 and International Biochar Initiative Standards version 2.0.

Publisher's note Springer Nature remains neutral with regard to jurisdictional claims in published maps and institutional affiliations. 